\title{
FABRICATION AND TESTING OF NON-VOLATILE MEMORY USING A CHALCOGENIDE GLASS THIN FILM
}

\author{
A Thesis \\ Presented to \\ the Faculty of California Polytechnic State University \\ San Luis Obispo
}

\author{
In Partial Fulfillment \\ of the Requirements for the Degree \\ Master of Science in Electrical Engineering
}

by

William Porter Dunn

May 2008 
(C) 2008

William Porter Dunn

ALL RIGHTS RESERVED 


\section{APPROVAL PAGE}

TITLE: DESIGN AND FABRICATION OF NON-VOLATILE MEMORY USING A CHALCOGENIDE GLASS THIN FILM

AUTHOR: William Porter Dunn

DATE SUBMITTED:

Dr. Fei Wang, Adviser and Committee Chair

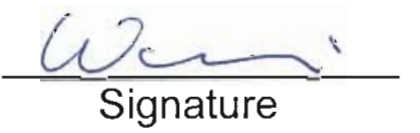

Dr. Richard Savage, Committee Member

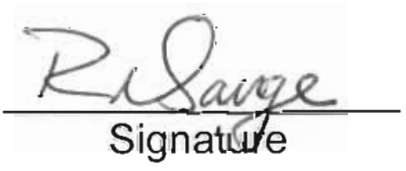

Dr. Xiaomin Jin, Committee Member

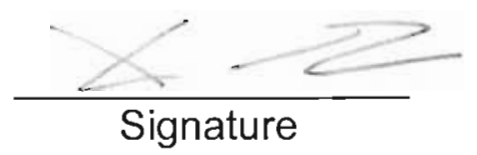




\begin{abstract}
:
FABRICATION AND TESTING OF NON-VOLATILE MEMORY USING A CHALCOGENIDE GLASS THIN FILM

By

William Porter Dunn
\end{abstract}

Silver doped chalcogenide glasses, such as Ag-Ge-Se, display resistance switching behavior under low threshold voltages, which makes these materials very promising in non-volatile memory applications. In this thesis, ternary glasses of composition $\left(\mathrm{GeS}_{3}\right)_{1-\mathrm{x}} \mathrm{Ag}_{\mathrm{x}}(\mathrm{x}=0.1$ and 0.2$)$ are studied. Non-volatile memory cells based on the above compositions are fabricated and electrically characterized.

Thin films are fabricated at 3 different evaporation angles $\left(45^{\circ}, 60^{\circ}\right.$, and $\left.90^{\circ}\right)$ in a vacuum thermal evaporator. Finished films are thermally annealed at $150^{\circ} \mathrm{C}$ and $200^{\circ} \mathrm{C}$ respectively. Both virgin and thermal annealed samples are examined using Raman scattering. Raman line-shapes of both virgin and thermal annealed samples display signature peaks corresponding to Ge-S tetrahedral and Ag-attached thiogermanate units, which confirms the composition of the thin films. Extra elemental sulfur peaks are recorded in all films because of sulfur's low vaporization temperature. Thermally annealed films show a dependency on deposition angle. We found elemental sulfur peaks (at $\sim 200 \mathrm{~cm}^{-1}$ ) could be removed by annealing at lower temperatures $\left(150^{\circ} \mathrm{C}\right)$ from films deposited at smaller angles, while higher temperature $\left(200^{\circ} \mathrm{C}\right)$ is needed to remove sulfur peaks from films deposited at $90^{\circ}$. This result indicates that the vertically deposited films are more condensed than the obliquely deposited ones. A condensed network needs more thermal energy for any structural adjustment, in this case, the release 
of elemental sulfur.

Non-volatile memory devices were fabricated with different film thickness from about $10 \mathrm{~nm}$ up to $120 \mathrm{~nm}$. Electrical characterizations of these devices show clear current switching behavior. The transition threshold voltage is around 0.353 Volts to 0.733 Volts with the average being around 0.526 Volts. While the transition threshold voltage does not rely on the film thickness, the current does. We observe that the peak writing current increases as a function of film thickness. 


\section{Acknowledgments:}

Without the help of a few key people this project and the opportunities that follows could not have happened and I owe them a great deal of gratitude. First is my advisor, Dr. Fei Wang, for allowing me to work on this project and giving me the opportunity to prove myself. Next are my project partners, Mukul Jain, Carter De Leo, and Nick Vickers; their hard work and time spent were integral to the success of the project. Thank you to Dr. Sergey Mamedov from Jovin Yvon in New Jersey for Raman Measurements. Also I'd like to thank Dr. Richard Savage for technical help and access to the clean room, as well as Cal Poly San Luis Obispo and the people in the Electrical Engineering and Material Engineering departments. Finally, I thank my parents for all the support given to me over the years.

Thank You All. 


\section{Table of Contents:}

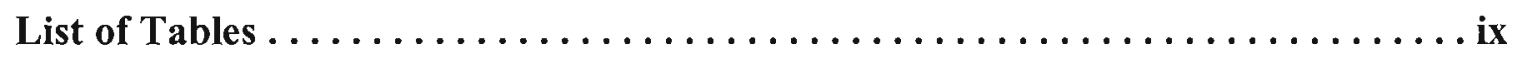

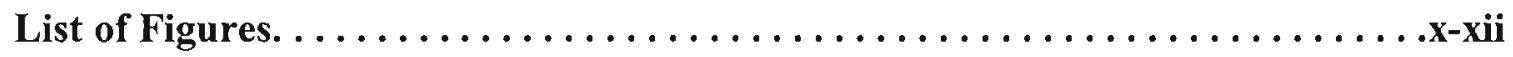

\section{Chapter 1: Introduction}

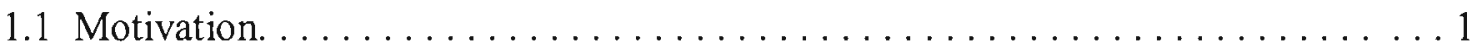

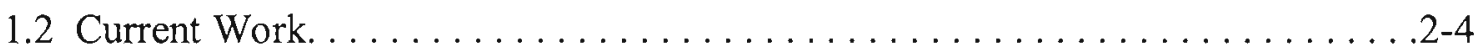

1.3 Thesis Outline. . . . . . . . . . . . . . . . . . . .

\section{Chapter 2: Background}

2.1 Non-Volatile Memory . . . . . . . . . . . . . . . . . . . . . . 6

2.2 Glass . . . . . . . . . . . . . . .

2.3 Chalcogenide Glass . . . . . . . . . . . . . . . . . . . . . . .

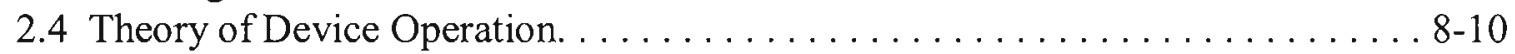

2.5 Thermal Evaporator . . . . . . . . . . . . . . . . . . . . . . . . . . . . . . $11-14$

2.6 Raman Scattering. . . . . . . . . . . . . . . . . . . . 14

\section{Chapter 3: Experimental Methods}

3.1 Chalcogenide Glass Sample Preparation . . . . . . . . . . . . . . . . 15

3.2 Thin Film Fabrication . . . . . . . . . . . . . . . . . . . . .

3.2.1 Normal Deposition . . . . . . . . . . . . . . . . . . . 16-20

3.2 .2 Oblique Deposition. ........................ . . . . 21

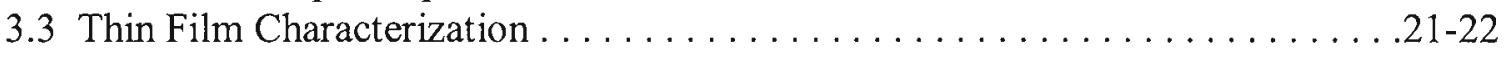

3.4 Thin Film Processing. . . . . . . . . . . . . . . . . . . . . . . 22-23

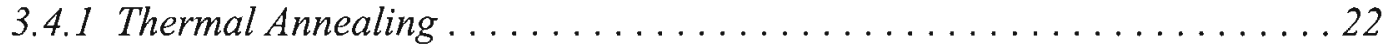

3.4 .2 Photo Annealing. . . . . . . . . . . . . . . . . . 22-23

3.5 Device Fabrication. . . . . . . . . . . . . . . . . . . . . . . 23-28

3.5.1 Aluminum Anode . . . . . . . . . . . . . . . . . . 24-25

3.5.2 Chalcogenide Glass Thin Film . . . . . . . . . . . . 26-27

3.5 .3 Silver Cathode. ...................... . 27-28

3.6 Device Testing. . . . . . . . . . . . . . . . . . . . . .

\section{Chapter 4: Results and Discussion}

4.1 Thin Film and Bulk Raman Results Comparison . . . . . . . . . . . . 31-36

4.2 SEM Results . . . . . . . . . . . . . . . . $\ldots \ldots \ldots \ldots$

4.3 Oblique Results. . . . . . . . . . . . . . . . . . . . . . $37-43$

4.3.1 Thickness . . . . . . . . . . . . . . . . . . . . . 37-40

4.3 .2 Raman Results for Virgin Samples. . . . . . . . . . . . . . 40 
4.3.3 Thermal Annealing . . . . . . . . . . . . . . . . . . . 40 40-42

4.3 .4 Photo Annealing . . . . . . . . . . . . . . . . . . . . 42-43

4.4 Device Results . . . . . . . . . . . . . . . . . . . . . . . . . . . . . . .43-49

Chapter 5: Concluding Remarks......................50-53

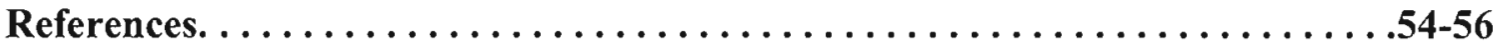




\section{List of Tables:}

1.1 Memory Characteristics. . . . . . . . . . . . . . . . . . . . 1

2.1 Sample Chalcogenide Glass Compositions. . . . . . . . . . . . . 8

3.1 Experimental Results for Current Required for Material Vaporization. . . . . . . . 16

3.2 Device Set Chalcogenide Glass Amounts . . . . . . . . . . . . . . 24

4.1 Comparison of Bulk Ag-Ge-S Glass and Ag-Ge-S Thin Film Glass Modes. . . . . .35

4.2 Heat of Vaporization. . . . . . . . . . . . . . . . . . . . . .

4.3 Amount of Glass per Device Slide . . . . . . . . . . . . . . . . . . .

4.4 Device Averages for Slide B-F. . . . . . . . . . . . . . . . . 


\section{List of Figures:}

1.1 SeGeAg Chalcogenide Glass Hysteresis Curve . . . . . . . . . . . . . 3

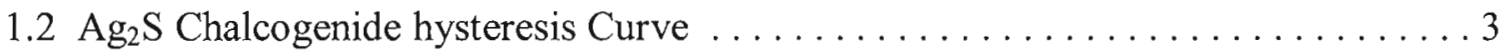

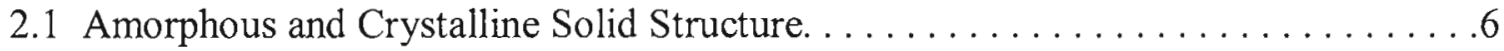

2.2 Periodic Table with Chalcogens Highlighted. . . . . . . . . . . . . .

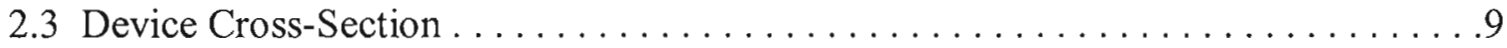

2.4 No Bias Voltage, High Resistance State. . . . . . . . . . . . . . . . . 10

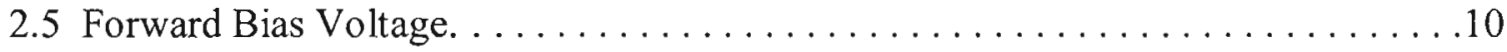

2.6 Forward Bias, low Resistance state. . . . . . . . . . . . . . . . . 10

2.7 Reverse Bias. . . . . . . . . . . . . . . . . . . . . . . . . 10

2.8 High Resistance State. . . . . . . . . . . . . . . . . . . . 10

2.9 Varian VE-10 Thermal Evaporator. . . . . . . . . . . . . . . . 12

2.10 Thermal Evaporator Base Plate. . . . . . . . . . . . . . . . 12

2.11 Beaker on Evaporator Base Plate. . . . . . . . . . . . . . . 13

2.12 Sample Holder. . . . . . . . . . . . . . . . . . . . . . 13

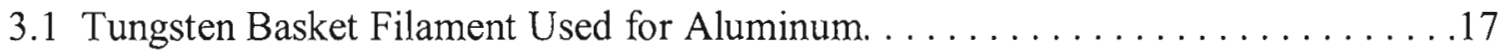

3.2 Molybdenum Boat Used for Silver. . . . . . . . . . . . . . . 17

3.3 Small Dimple Boat. . . . . . . . . . . . $\ldots \ldots \ldots \ldots \ldots \ldots \ldots \ldots \ldots \ldots$

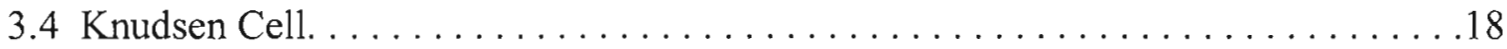

3.5 Tubular Boat. . . . . . . . . . . . . . . . . . . . . . .

3.6 Layout of Glass Slides Inside Beaker. . . . . . . . . . . . . . . 20

3.7 Device Cross-Section. . . . . . . . . . . . . . . . . . . 23

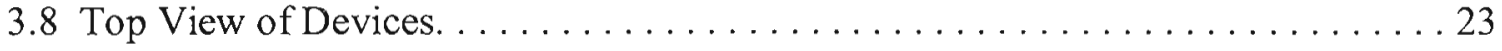




\section{List of Figures:}

3.9 Tungsten Basket Filament Used for Aluminum. . . . . . . . . . . . . 24

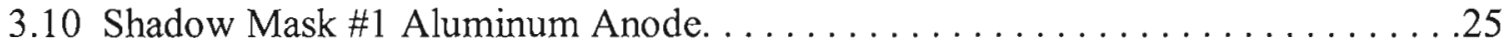

3.11 Device Cross Section, Aluminum Anode. . . . . . . . . . . . . . . . 25

3.12 Tubular Boat. . . . . . . . . . . . . . . . . . . . . . . .

3.13 Shadow Mask $\# 2$ Chalcogenide Glass layer. . . . . . . . . . . . . . . . 26

3.14 Device Cross Section, Aluminum Anode and Chalcogenide Glass Thin Film. . . 27

3.15 Molybdenum Boat Used for Silver. . . . . . . . . . . . . . . . 28

3.16 Completed Device Cross Section. . . . . . . . . . . . . . . . 28

3.17 Signatone S-250 Test Bench and Keithley 2400 Source Meter. . . . . . . . . . . . 29

3.18: Device Testing Interface. . . . . . . . . . . . . . . . . . 30

4.1 Raman Results for Ag-Ge-S Glass Thin Film (10\% Silver). . . . . . . . . . . . . 32

4.2 Raman Results for Ag-Ge-S Glass Thin Film (20\% Silver) . . . . . . . . . . . 32

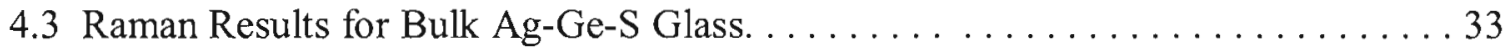

4.4 Raman Results Deconvolution for Bulk Ag-Ge-S (20\% silver). . . . . . . . . . . 33

4.5 Raman Results Deconvolution for Thin Film Ag-Ge-S (20\% silver) . . . . . . . . 34

4.6 SEM Picture of Ag-Ge-S Glass Thin Film $(20 \%$ silver $) \ldots \ldots \ldots \ldots \ldots \ldots$

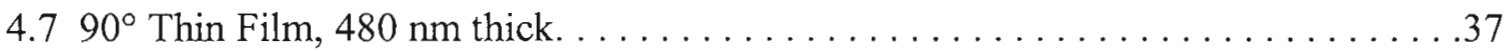

$4.860^{\circ}$ Thin Flim, $650 \mathrm{~nm}$ thick. . . . . . . . . . . . . . . . .

$4.945^{\circ}$ Thin Flim, 900 nm thick. . . . . . . . . . . . . . . . . . . .

4.10 Original Sample holder Beaker and Shorter Sample Holding Beaker. . . . . . . . 39

4.11 Raman Results from Virgin $45^{\circ}, 60^{\circ}$ and $90^{\circ}$ Slide. . . . . . . . . . 40

4.12 Raman Results from $45^{\circ}, 60^{\circ}$ and $90^{\circ}$ slide @ $150^{\circ} \mathrm{C} \ldots \ldots \ldots \ldots \ldots \ldots$ 


\section{List of Figures:}

4.13 Raman Results from $45^{\circ}, 60^{\circ}$ and $90^{\circ}$ slide @ $200^{\circ} \mathrm{C} \ldots . . . \ldots \ldots \ldots . . . . . .41$

4.14 Raman Results from $45^{\circ}, 60^{\circ}$ and $90^{\circ}$ slide @ $200^{\circ} \mathrm{C} \ldots . . \ldots \ldots \ldots \ldots . \ldots . \ldots 42$

4.15 Hysteresis Curve. . . . . . . . . . . . . . . . . . . . . . . . . .43

4.16 Current vs Voltage Device D3 $1^{\text {st }}$ Cycle. . . . . . . . . . . . . . 44

4.17 Current vs Voltage Device D3 $2^{\text {nd }}$ Cycle. . . . . . . . . . . . . 44

4.18 Current vs Voltage Device D3 $3^{\text {rd }}$ Cycle. . . . . . . . . . . . . . 45

4.19 Current vs. Amount of Glass. . . . . . . . . . . . . . . . 47

4.20 Narrowing of Hysteresis Curve Over Three Read/Write Cycles Device C3 . . . . 48

4.21 Narrowing of Hysteresis Curve Over Three Read/Write Cycles Device C10 . . . 48

4.22 Shorted Device. . . . . . . . . . . . . . . . . . . . . . . . . 49

4.26 Failure Mode of $\mathrm{Ag} 2 \mathrm{~S}$ Device. . . . . . . . . . . . . . . . 49 


\section{Chapter 1: Introduction}

\subsection{Motivation}

Currently the most popular non-volatile memory technology is a MOS transistor with a floating gate (Flash memory). While flash memory is an effective solution, it has some limitations, such as slow read/write speeds, degradation of stored information over time, high power consumption due to leakage current and limited amounts of read/write cycles. ${ }^{1,2}$ Therefore, the demand for memory based on different mechanisms is increasing.

The "new" technologies available include ferroelectric, magnetoresistive, metal shape memory, phase change memory and programmable metallization cells. Table 1.1 is a list of characteristics for different non-volatile memory mechanisms ${ }^{1,2}$. Of these,

\begin{tabular}{|c|c|c|c|c|c|}
\hline Parameter & Flash & Ferroelectric & Magnetoresistive & PCM & PMC \\
\hline Endurance (cycles) & $10^{\wedge} 6$ & $10^{\wedge} 16$ & $10^{\wedge 14}$ & $10^{\wedge} 12$ & $10^{\wedge} 10$ \\
\hline ReadWrite Voltages (V) & $2.0 / 12.0$ & $1.5 / 1.5$ & $3.3 / 3.3$ & $0.4 / 1.0$ & $0.1 / 0.25$ \\
\hline ReadWrite speeds (ns) $)$ & 20.011000 .0 & $40.0 / 40.0$ & $50.0 / 50.0$ & $50.0 / 50.0$ & $35.0 / 35.0$ \\
\hline Stucture & Complex & Complex & Complex & Simple & Simple \\
\hline \multicolumn{7}{|c|}{ Table 1.1: Memory Characteristics } \\
\hline
\end{tabular}

phase change memory and programmable metallization cells has clear advantages over other promising technologies. They have the simplest fabrication, the fastest read/write speeds, high endurance and low power consumption. Both of these two technologies use chalcogenide glasses as an active layer. 


\subsection{Current Work in Chalcogenide Based Non-Volatile Memory}

Phase change memory (PCM) works by forcing semiconductor material to switch between an amorphous state (high resistivity) and a crystalline state (low resistivity). ${ }^{3}$

This could be done by laser melting (e.g. DVD discs) or by applying voltage bias (e.g. phase change random access memory and programmable metallization cell). ${ }^{4}$

Commercialized chalcogenide memory devices are based on chalcogenide glasses containing $\mathrm{Sb}$ and $\mathrm{Te}$. Because the data storage relies on changing the material between crystal and amorphous phases, these devices required longer switching time (around 50 ns) and higher energy dissipation because it requires heating and melting by laser beam. ${ }^{4,5}$ This is the technology used in reading and writing DVD discs. ${ }^{4,5}$

Programmable metallization cells (PMC) rely on a different mechanism than phase change memory, but it still varies between a high resistive state and a low resistive state. ${ }^{6}$ A previous work done at Arizona State University and the University of Cincinnati has shown that a chalcogenide glass device consisting of a SeGeAg layer between an active $\mathrm{Ag}$ electrode and an inert $\mathrm{W}$ electrode has the switching curve seen below in figure $1.1^{7}$. The advantage of this device is that it can switch between the two states using a small bias voltage instead of heating and cooling with a laser or other source. This reduces the power consumption and the complexity of the writing process. Also, the read/write speeds of PMCs (35 ns) are slightly faster than PCMs $(50 \mathrm{~ns}) .^{9}$ 


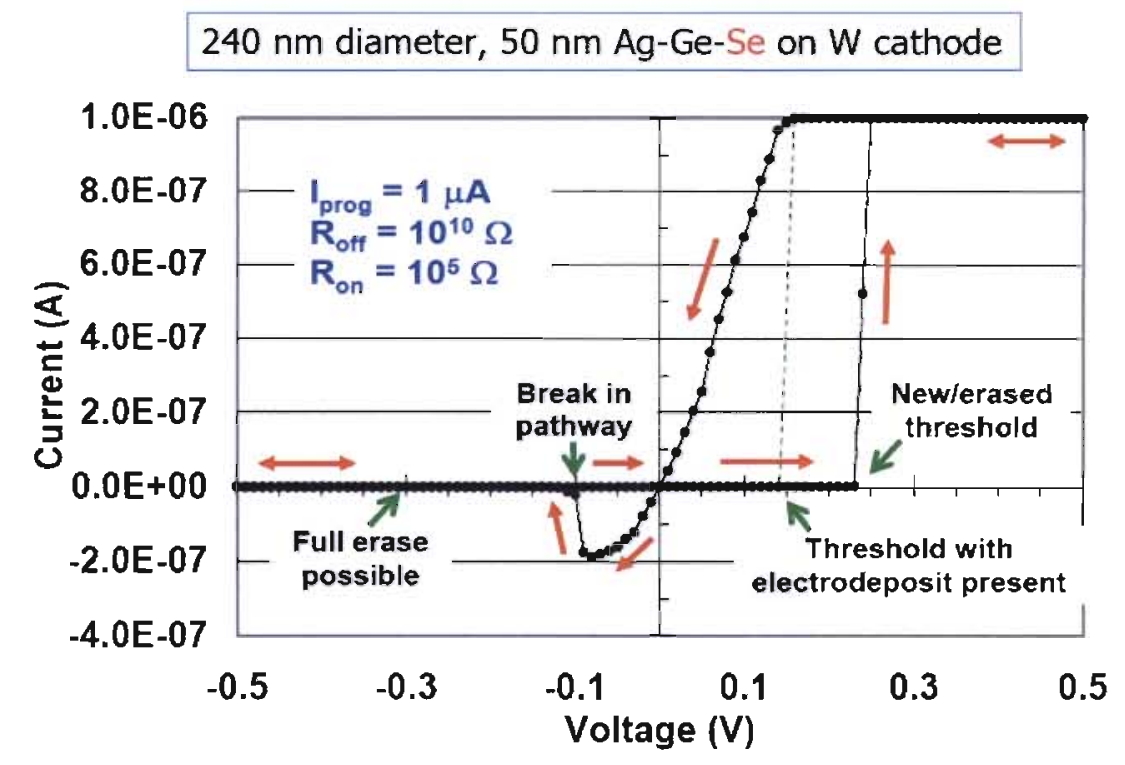

Figure 1.1: SeGeAg Chalcogenide Glass Hysteresis Curve

Francis Bitter Magnet Lab at MIT in Cambridge, MA also worked on chalcogenide glass based devices. This group is working with a chalcogenide glass of composition $\mathrm{Ag}_{2} \mathrm{~S}$.

Figure 1.2 is a current vs. voltage curve for one of their devices. This work was presented at the American Physical Society March meeting in 2006. ${ }^{10}$

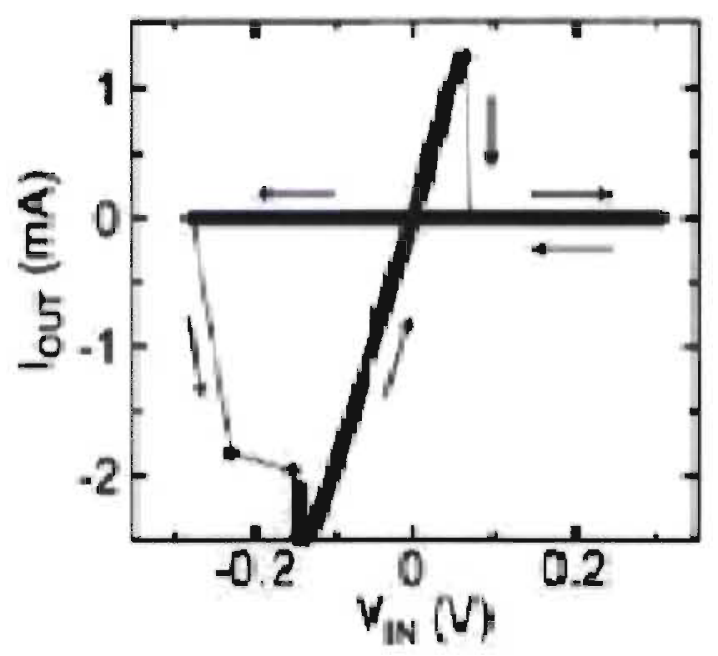

Figure 1.2: $\mathrm{Ag}_{2} \mathrm{~S}$ Chalcogenide hysteresis Curve ${ }^{10}$ 
While this group did not present any information about the read/write times of the device or its endurance, they did show that the device needed a minimum thickness $120 \mathrm{~nm}$ of

the chalcogenide glass layer in order to function properly. ${ }^{10}$ Dr. J.S. Moodara, supervisor of this MIT group, has kindly provided us the shadow masks used in fabrication of this project's devices.

\subsection{Thesis Outline}

In this thesis, we are presenting the design and fabrication of a PMC device based on a chalcogenide glass consisting of GeAgS. Sulfide devices have many advantages over the Selenide devices, they exhibit stability at higher temperatures $\left(\sim 400^{\circ} \mathrm{C}\right.$ for sulfur and $200^{\circ} \mathrm{C}$ for Selenium) and a potentially faster transitions between the high resistive state and the low resistive state ${ }^{2}$. However, Sulfides are challenging in fabrication because of sulfur's high vapor pressure and low vaporization temperature. The aforementioned properties of sulfur create a problem in the growth of the thin film if mixed with other elements. In general it can result in inconsistencies in the film.

The project has two objectives. The first objective is to deposit thin films of GeAgS using a custom built Varian thermal evaporator on glass slides, then analyze the thin film using Raman spectroscopy and compare those results with the results of bulk samples of the same chalcogenide glass. The bulk sample of GeAgS used in this project was prepared at the University of Cincinnati. For the second objective actual memory devices are fabricated using the same evaporator for all steps. The devices that are fabricated will have a varying thickness of chalcogenide glass to help determine an 
optimal thickness. Varying the thickness of the chalcogenide glass will give an insight as to how thickness affects the speed of the device, current draw of the device and $\mathrm{read} / \mathrm{write}$ voltages of the device. After fabrication all the devices will be tested and data will be analyzed. The project will help in identifying various properties associated with these memory devices such as its hysteresis curve and turn on voltage. 


\section{Chapter 2: Background Information}

\subsection{Non-Volatile Memory}

Non-volatile memory is any form of electronic memory that does not require power for data retention. Even after power is completely removed from the device it can retain stored information.

\subsection{Glass}

A glass is also called an amorphous solid. An amorphous solid is defined as any solid that only shows a short range order molecular structure, but does not show any long or medium range order. This is different than a crystalline solid. A crystalline solid has short, medium and long-range order. Figure 2.1 shows the structure

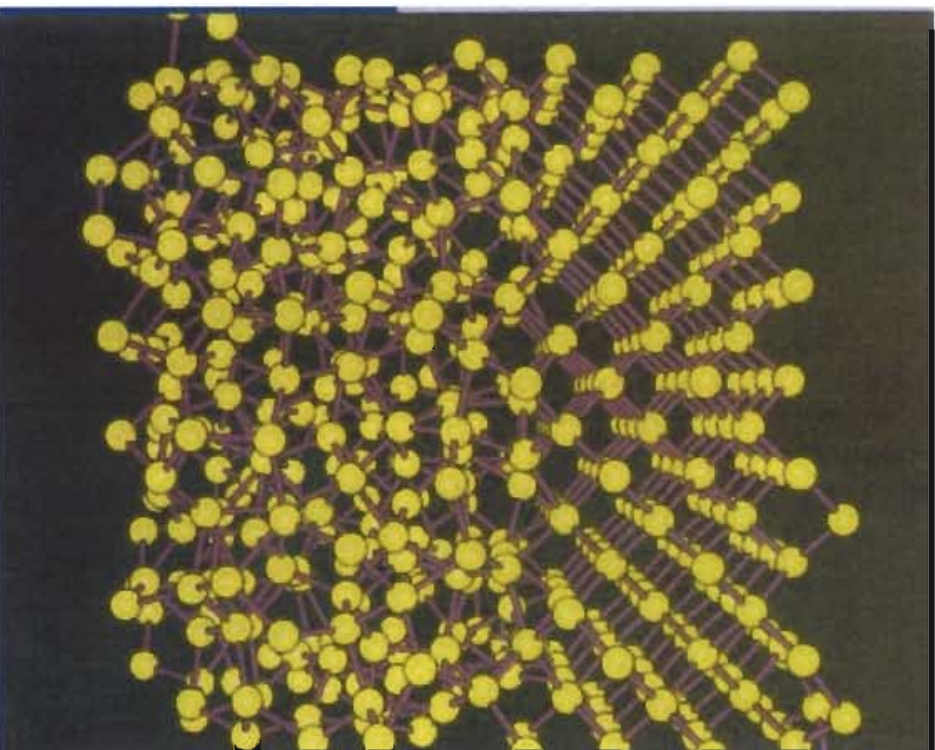

Figure 2.1: Amorphous and Crystalline Solid Structure ${ }^{11}$ 
of an amorphous solid on the left compared to a crystalline solid on the right. ${ }^{11}$ As can be expected each structure displays different electrical characteristics. Since amorphous

solids have no defined structure electrons travelling through the material tend to be scattered more often, hence amorphous structures have a higher resistance. The opposite is true for crystalline solids because it has such a highly ordered structure there are fewer electron scattering sites for electrons to encounter and therefor a lower resistance.

\subsection{Chalcogenide Glass}

A chalcogenide glass is a glass containing chalcogenides, namely, elements from group VI of the Periodic table such as $\mathrm{S}, \mathrm{Se}$, Te or Po. ${ }^{11}$ Chalcogenides are materials containing elements from group VI of the periodic table, namely,

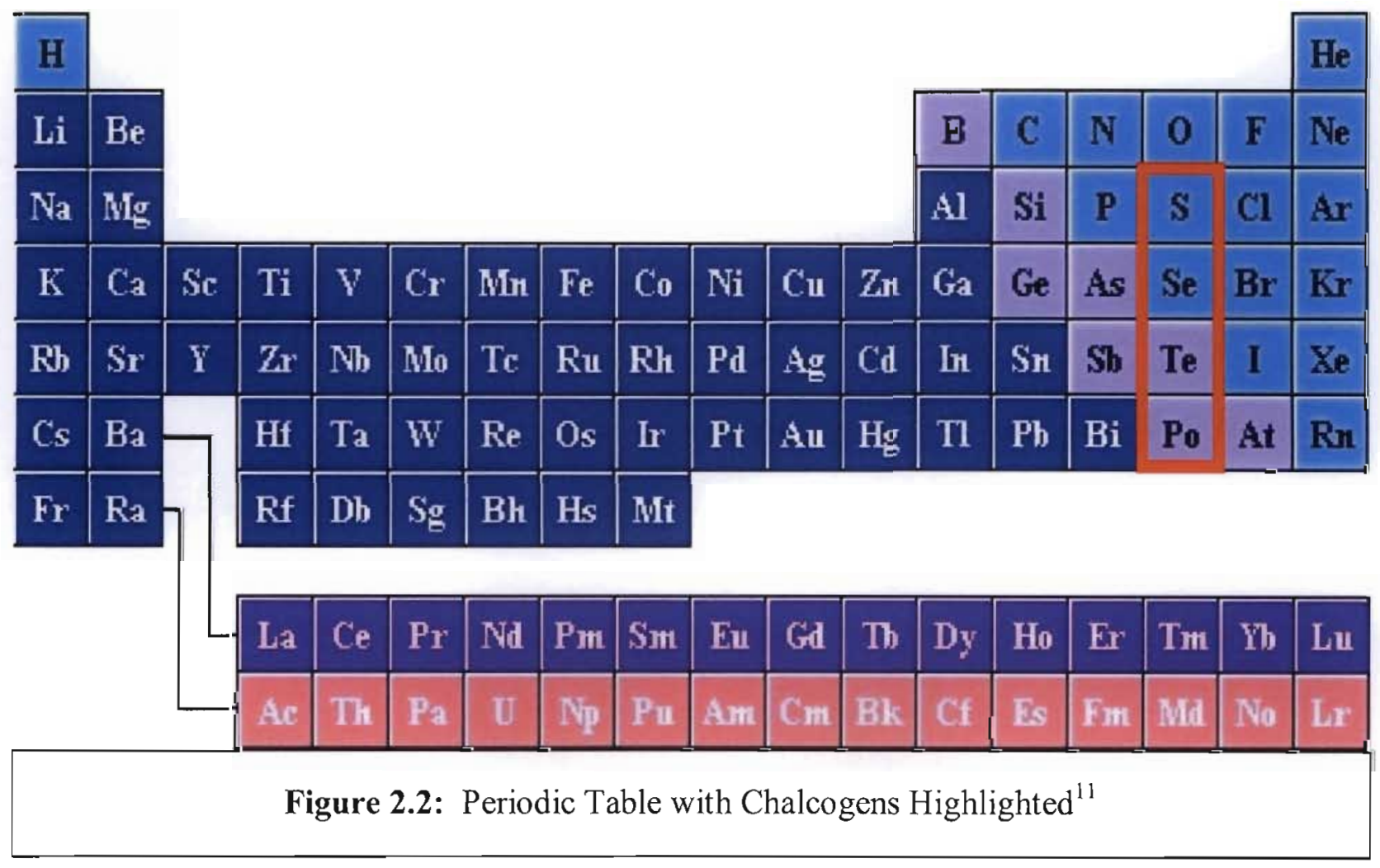


Chalcogenides can form good glasses on a wide range of compositions as can be seen in table 2.1. ${ }^{1,10,12,25}$ Therefore, the physical and electrical properties of chalcogenides glasses can be fine tuned by adjusting their chemical compositions. ${ }^{8}$ This is a significant advantage over their crystalline counterparts, where crystals can be only formed at certain compositions.

\begin{tabular}{|c|}
\hline $\begin{array}{l}\text { Chalcogenide Glass } \\
\text { Compositions }\end{array}$ \\
\hline$B e_{x} S e_{y}$ \\
\hline$S n_{x} M n_{y} T e_{z}$ \\
\hline $\mathrm{Ag}_{x} \mathrm{Ge}_{y} \mathrm{Se}_{z}$ \\
\hline $\mathrm{Ge}_{2} \mathrm{Sb}_{2} T \mathrm{e}_{5}$ \\
\hline $\mathrm{Cu}_{x} \mathrm{Ge}_{y} \mathrm{Se}_{z}$ \\
\hline $\mathrm{A}_{\mathrm{w}} \mathrm{G} \mathrm{e}_{x} \mathrm{~A} \mathrm{~s}_{y} \top \mathrm{e}_{z}$ \\
\hline $\mathrm{As}_{\mathrm{X}} \mathrm{G} \mathrm{e}_{\mathrm{Y}} \mathrm{T} \mathrm{e}_{z}$ \\
\hline $\mathrm{As}_{2} \mathrm{Se}_{3}$ \\
\hline$A_{s} S_{i} T e_{z}$ \\
\hline$A g_{x} G e_{y} S_{z}$ \\
\hline
\end{tabular}

Table 2.1: Sample Chalcogenide Glass Compositions ${ }^{1,10,12,25}$

\subsection{Theory of Device Operation}

The PMC device geometry consists of three layers, an Aluminum layer, a chalcogenide glass layer and a Silver layer all on top of a glass substrate (figure 2.3). The first layer of the device is an inert Aluminum layer that acts as the anode. On top of the anode comes the chalcogenide glass layer or so the called the "memory film". 


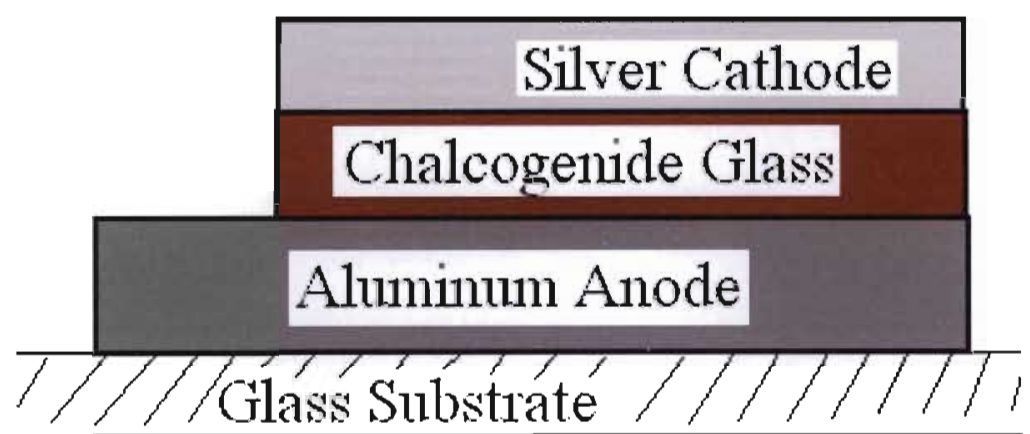

Figure 2.3: Device Cross-Section

This is the portion of the device that varies between a high resistance and low resistance state. The final layer is a semi active layer of Silver that acts as the cathode of the device.

The device operates by varying its resistance between a high and low state under low biasing voltages. When a forward bias voltage is applied to the electrodes the ionized silver in the chalcogenide thin film migrates towards the cathode until it forms small conducting pathways between both electrodes. This is the low resistance state. Placing a reverse bias on the electrodes disassociates the silver conduction pathways returning the chalcogenide thin film back to a high resistance state ${ }^{11}$. Figure 2.4 through 2.8 is an illustration of the operation of the device. ${ }^{13}$ The resistance state of the device determines the information stored as either a 1 or 0 . 

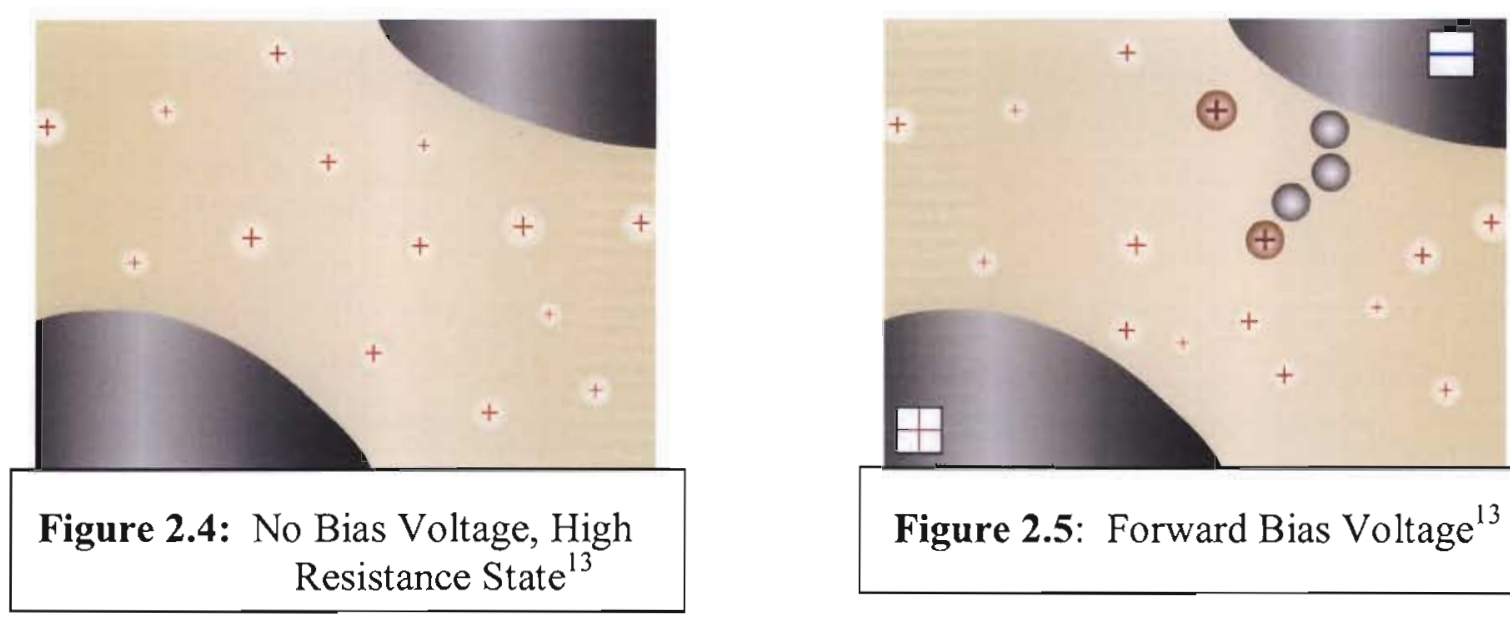

Figure 2.5: Forward Bias Voltage ${ }^{13}$
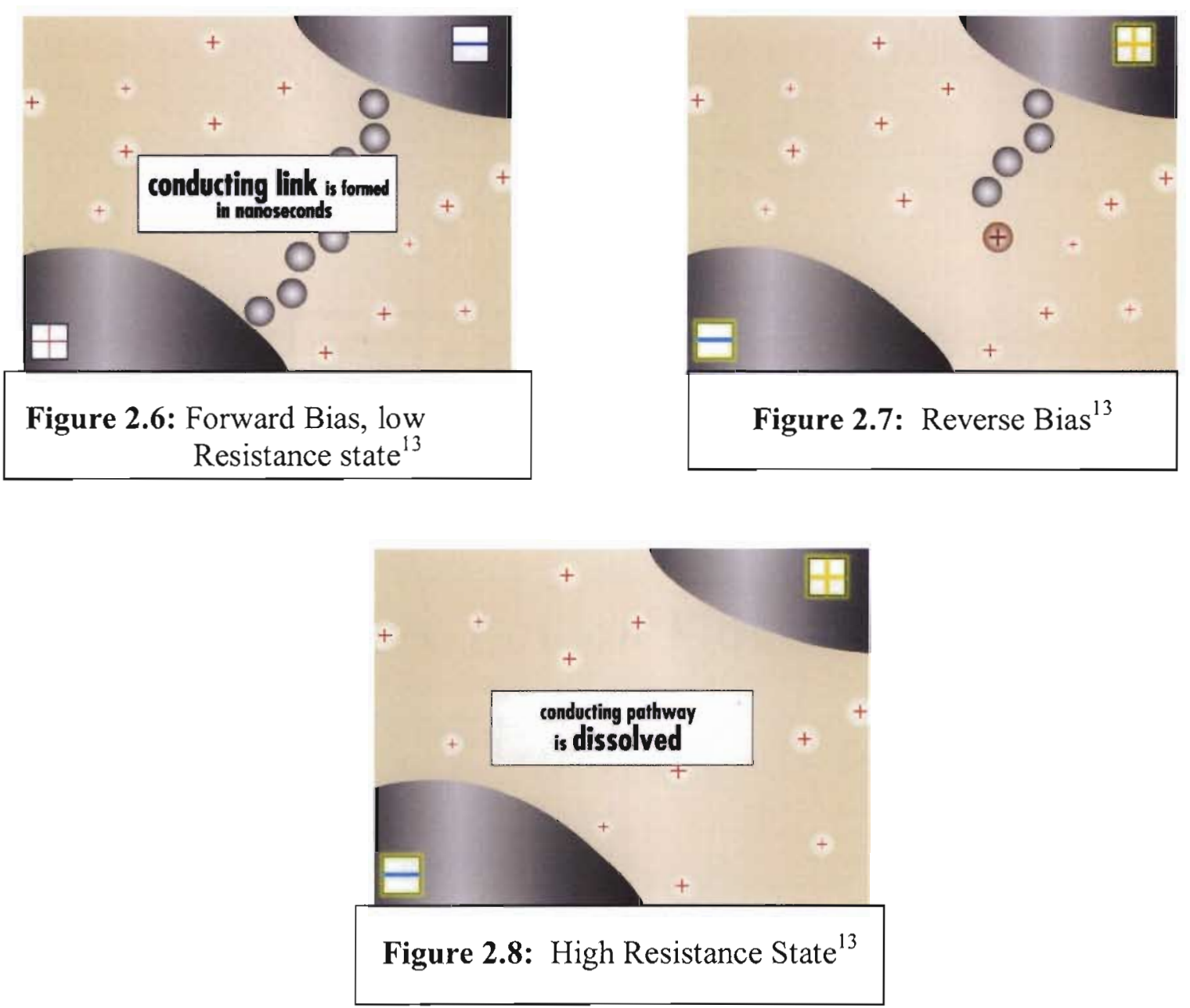


\subsection{Thermal Evaporator}

A thermal evaporator is a machine that is used for growing thin films. It contains a vacuum chamber, several pairs of electrodes and a substrate holder. Between the two electrodes sits a filament/boat that holds materials for evaporation. A large current passes through the boat, which heats it up rapidly, boiling the material. Once the material is in a gaseous form it settles on the cooler substrate and the inside of the vacuum chamber forming a thin film of similar composition.

The thermal evaporator used in this project is a customized Varian model VE-10 vacuum evaporator located in the class 1000 clean room. Its main vacuum pump is a turbo molecular pump. The turbo pump is connected to a vacuum fore line valve, which is used for sealing the vacuum chamber. A mechanical backing pump is connected to the fore line valve. At the beginning, time trials showed the evaporator pumped down to a pressure around $3.5 \times 10-5$ torr in 5 hrs. The pressure is adequate but the pump down time is not. So the backing vacuum pump for the vacuum chamber and the air compressor used for controlling the vacuum fore line valve were changed and the time to get to $3.5 \times 10-5$ torr dropped to $1.5-2$ hrs. This was because the air compressor that controlled the vacuum fore line could not keep up a constant pressure so the vacuum fore line value would intermittently shut down and the backing pump was shot and did not have good suction.

Figure 2.9 is a picture of the actual evaporator deposition chamber. The main components are the base plate, sample holder, beaker and bell jar. The base plate is a stainless steel plate with two sets of electrodes, ion gauge tube input and an opening for the attached turbo molecular pump (see figure 2.10). The vacuum/deposition chamber 
is a bell jar with a beaker placed upside-down over the electrode. The beaker is 10

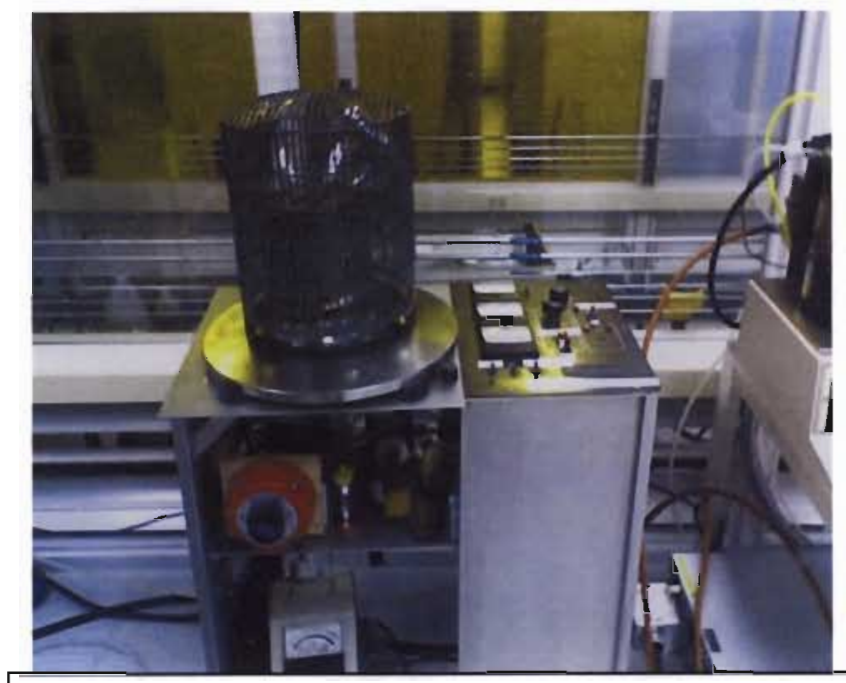

Figure 2.9: Varian VE-10 Thermal Evaporator

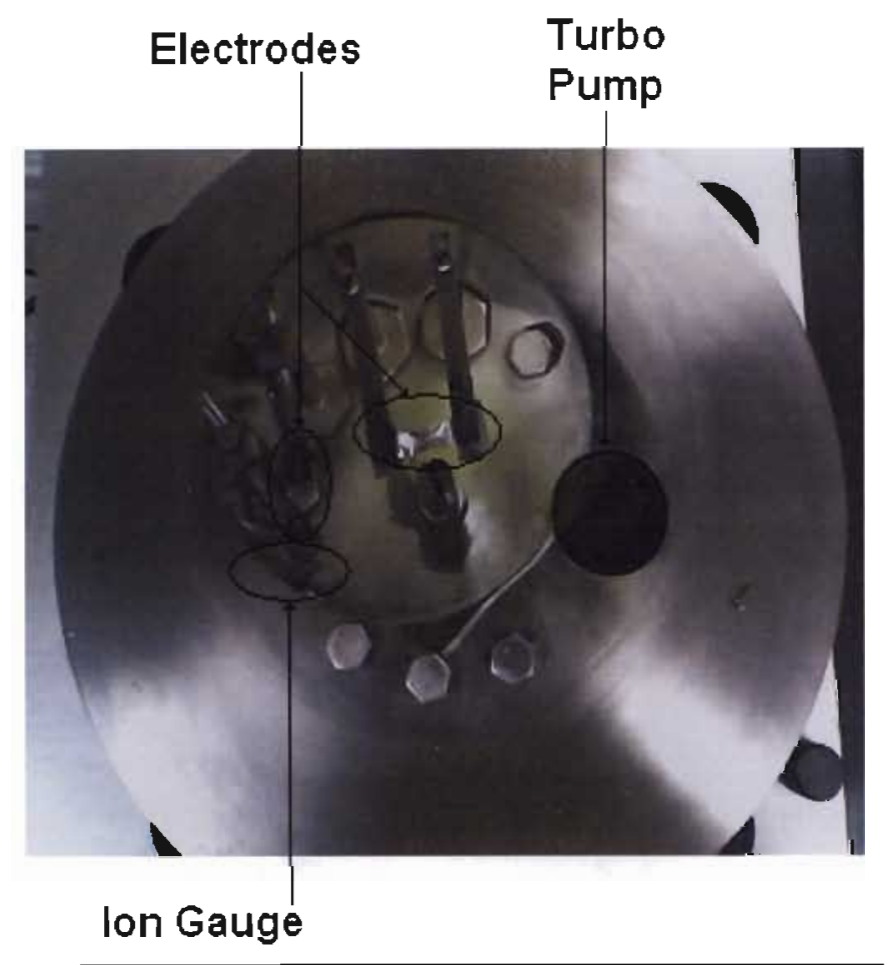

Figure 2.10: Thermal Evaporator Base Plate 
$15 / 16$ " tall with a 6 " diameter with a 4.1 " hole cut into the bottom of the beaker (see

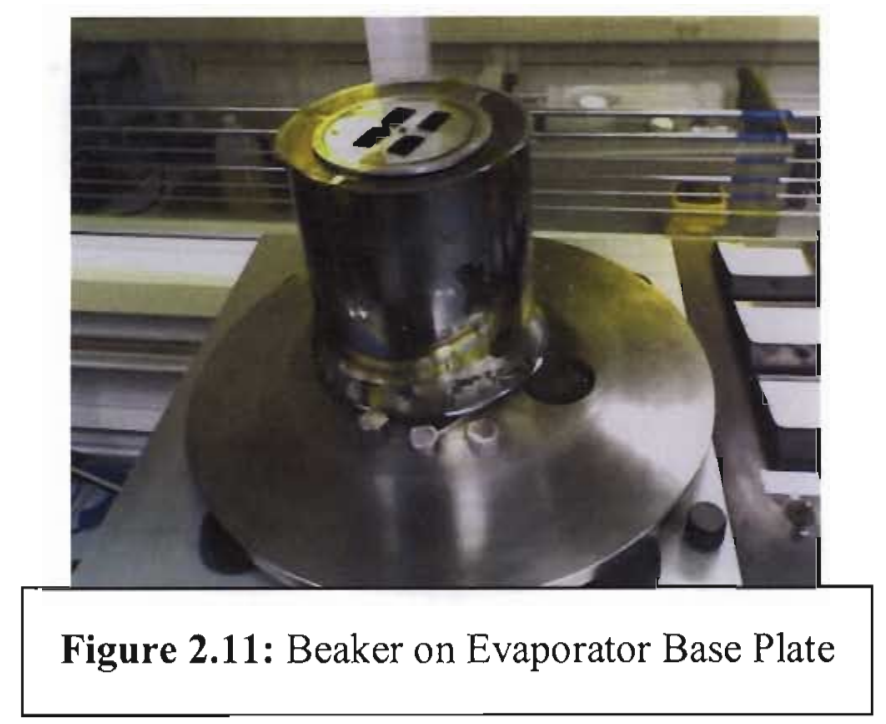

figure 2.11). The hole in the bottom of the beaker is for holding a 4" wafer. Our sample holder is a round plexiglass plate (4" in diameter) with four rectangular holes cut into it using a dremal hand drill (see figure 2.12). It was decided to use plexiglass as the

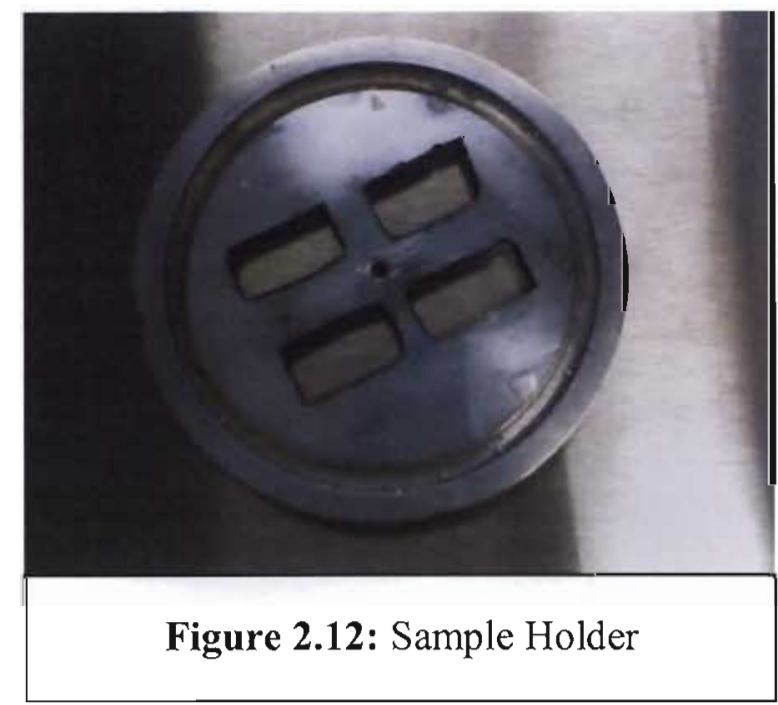

sample holder because it is easy to work with given the tools available, even though it 
might not be the most ideal material for use in a vacuum chamber. Our substrates (glass microscope slides) were taped down using Kapton tape, a tape certified for clean room use.

\subsection{Raman Scattering}

Raman scattering in solids is caused by the interaction between light (photons) and lattice vibrations (phonons) with frequencies between 10 and $1000 \mathrm{~cm}^{-1}$. It is used for basic investigation of semiconductors and can yield information about phonon frequencies directly, energies of electron states through resonant effects and electronphonon interaction through line-shapes. Raman scattering is a powerful method to analyze different molecular building blocks in complex materials, since each molecular structure give their signature resonance frequency, which results in certain Raman shifts. Using Raman scattering in combination with EDS, we can not only determine the mole composition of the thin film, but also analyze the molecular building blocks of the thin film to make sure they reproduce the bulk materials' structure. ${ }^{14}$

The Raman scattering spectroscope used for the analysis of the samples was built by Jobin Yvon. The laser used was a He-Ne laser $(632.8 \mathrm{~nm})$ with $0.6 \mathrm{mw}$ of power with a $600 \mathrm{gr} / \mathrm{mm}$ grating. The objective image was $\times 100$ and the resolution maximum is 0.2 $\mathrm{cm}^{-1} /$ pixel. 


\section{Chapter 3: Experimental Methods}

\subsection{Chalcogenide Glass Sample Preparation}

All of the chalcogenide glass samples used in this experiment were synthesized at the University of Cincinnati. Measured amounts of Ag, Ge and S are loaded into a quartz tube, which is pumped down to $10^{-7}$ torr and sealed. The sealed materials are alloyed at $950^{\circ} \mathrm{C}$ for 72 hours and watered quenched. The vials are then shipped to Cal Poly State University San Luis Obispo.

There are two vials of $\mathrm{Ag}-\mathrm{Ge}-\mathrm{S}$ chalcogenide glass, one is a $10 \%$ silver composition $\left[\mathrm{Ag}_{0.1}\left(\mathrm{Ge}_{.75} \mathrm{~S}_{.25}\right)_{0.9}\right]$ and one is a $20 \%$ silver composition $\left[\mathrm{Ag}_{0.2}\left(\mathrm{Ge}_{.75} \mathrm{~S}_{25}\right)_{0.8}\right]$. The quartz vials are opened following a special procedure. Each of the two vials was dipped in liquid nitrogen, causing the material inside to contract faster then the quartz tube and therefore away from the tube walls. Then the vials are broken open and carefully picked through with tweezers, separating the broken quartz tube from the chalcogenide glass. After separation the chalcogenide glass was stored in a small glass vial, which in turn was stored in a portable vacuum container containing several desiccant packages. Storing the materials this way reduces the risk of oxides. There has not been that much research on the chalcogenide glass Ag-Ge-S so the effects of oxidization are not well known. In any case reducing oxide growth reduces the chance that the oxygen will cause any unwanted anomalies in the thin film. In total both vials contained around $4 \mathrm{~g}$ of glass. 


\subsection{Thin Film Fabrication}

\subsubsection{Normal Deposition}

The devices to be fabricated consist of three different thin film layers: an inert Aluminum electrode, a layer of chalcogenide glass $\left[\mathrm{Ag}_{x}\left(\mathrm{Ge}_{.75} \mathrm{~S}_{25}\right)_{1-\mathrm{x}}\right]$ and finally a layer of silver. The growth of the three thin films requires the answering of two questions: what is a suitable amperage of evaporation each material; second, how much material is needed to grow the desired thickness of film.

Each of the three materials $\mathrm{Al},(\mathrm{GeAgS})$ and $\mathrm{Ag}$ has its own heat of vaporization $290 \mathrm{~kJ} / \mathrm{mol}^{15},(334,250.58,45) \mathrm{kJ} / \mathrm{mol}^{16,17,18}$ and $250.58 \mathrm{~kJ} / \mathrm{mol}^{17}$ respectively. The different heat of vaporizations means that each of the three materials used requires different amounts of materials and different temperatures to achieve a similar film thickness. Different temperatures equal different amounts of current needed, table 3.1

\begin{tabular}{|c|c|}
\hline Material & $\begin{array}{c}\text { Current } \\
\text { (Amps) }\end{array}$ \\
\hline Aluminum, Al & 60 \\
\hline Silver, Ag & 80 \\
\hline Chalcogenide & 100 \\
Glass, Agx(Ge.75S.25)1-x] & \\
\hline
\end{tabular}

Table 3.1: Experimental Results for Current Required for Material Vaporization

shows the experimental results of the current required to vaporize each of the given material. $\mathrm{Al}$ and $\mathrm{Ag}$ were used initially as the primary test material this was because of the limited amounts of chalcogenide glass $\left[\mathrm{Ag}_{0.2}\left(\mathrm{Ge}_{.75} \mathrm{~S}_{.25}\right)_{0.8}\right]$ and $\left[\mathrm{Ag}_{0.1}\left(\mathrm{Ge}_{.75} \mathrm{~S}_{.25}\right)_{0.9}\right]$ that are available. 
For each deposition two microscope slides have strips of glass masked off with Kapton tape, then are secured to the sample holder over the holes using more Kapton tape. Masking off the glass creates sharp edges in the thin film, which helps to simplify measuring the thickness of the chalcogenide film. Using a tungsten basket filament like the one seen in figure 3.1, a thin film of aluminum roughly a micron in thickness is grown using $8 \mathrm{~cm}$ of 14 gauge aluminum wire. ${ }^{19}$ The Aluminum thin film is deposited at

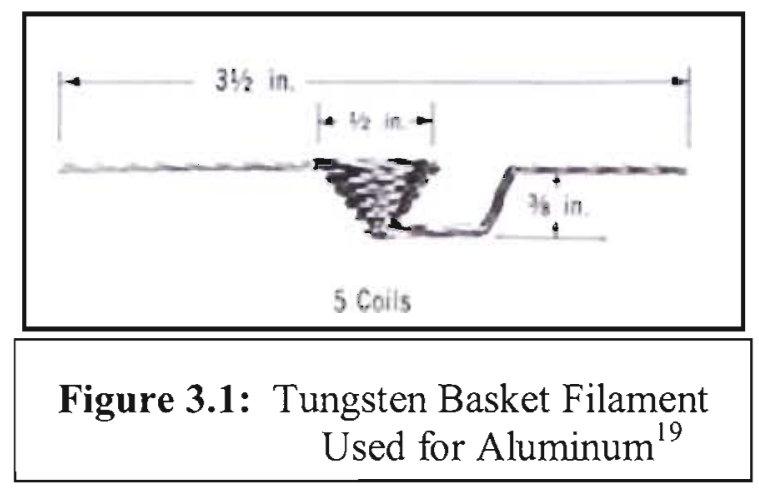

a pressure of $3.5 \times 10^{-5}$ torr while running $60 \mathrm{amps}$ of current through the filament until all the material was evaporated. Figure 3.2 is a picture of the molybdenum boat used for

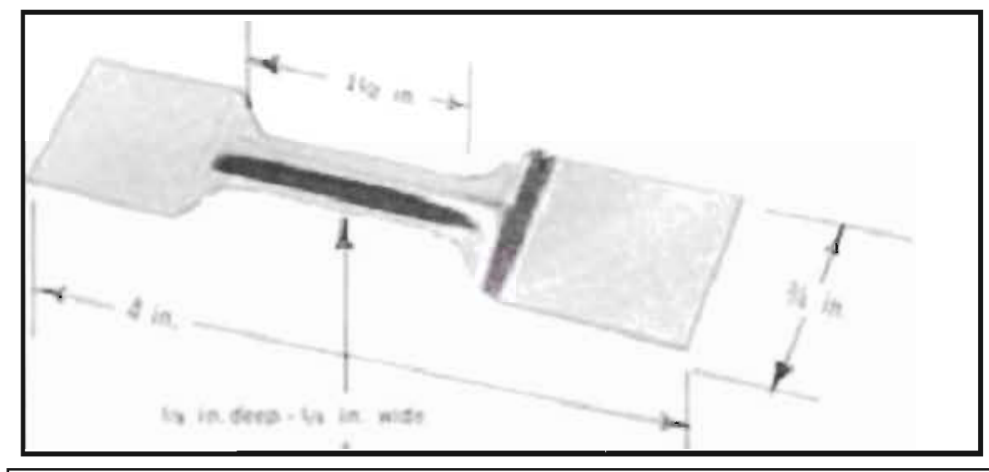

Figure 3.2: Molybdenum Boat Used for Silver ${ }^{20}$ 
depositing a silver thin film about 1 micron thick using $10 \mathrm{~cm}$ of 14 gauge silver wire. ${ }^{20}$ The silver thin film is deposited at a pressure of $3.5 \times 10^{-5}$ torr with 80 amps of current running through the boat. The current is not turned off until the silver is fully evaporated.

Evaporating the chalcogenide was more difficult than the silver or aluminum. For the first attempt, about $50 \mathrm{mg}$ of the $10 \%$ silver mixture was loaded into a tungsten boat of the same shape and dimensions as the boat seen in figure 3.2. The vacuum chamber pressure was brought down to $3.5 \times 10^{-5}$ torr and 60 amps of current was run through the boat. Not long after the ramp up of current through the boat, the chalcogenide glass material began exploding and popping out of the boat. The same experimental setup was repeated but when heating up the material the current was ramped up real slow. This still caused the chalcogenide to be expelled from the boat. During this trial a little of the material fell in the ion gauge tube blowing out the tube. This problem was further avoided by placing a little piece of steel mesh over the ion pressure gauge tube entrance.

Four more experiments in growing chalcogenides thin films were performed using
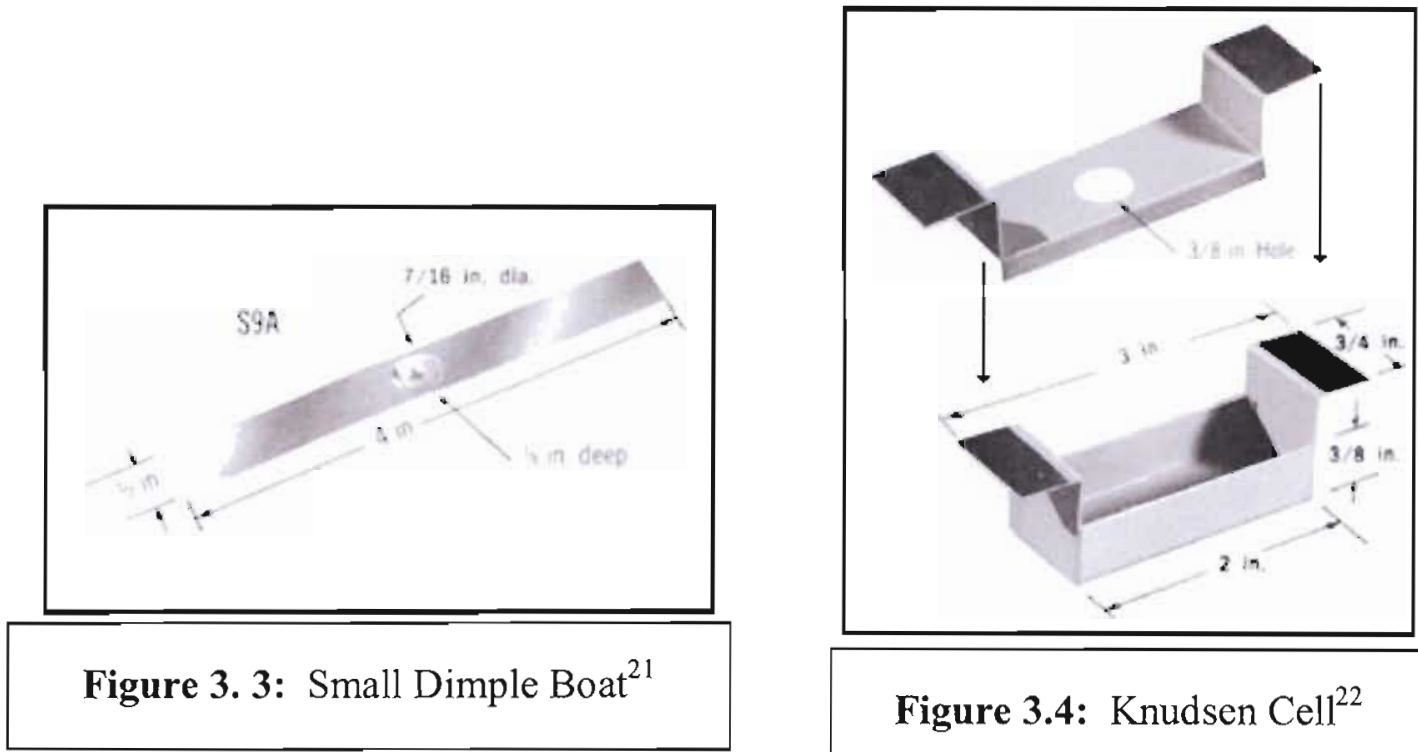

Figure 3.4: Knudsen Cell ${ }^{22}$ 


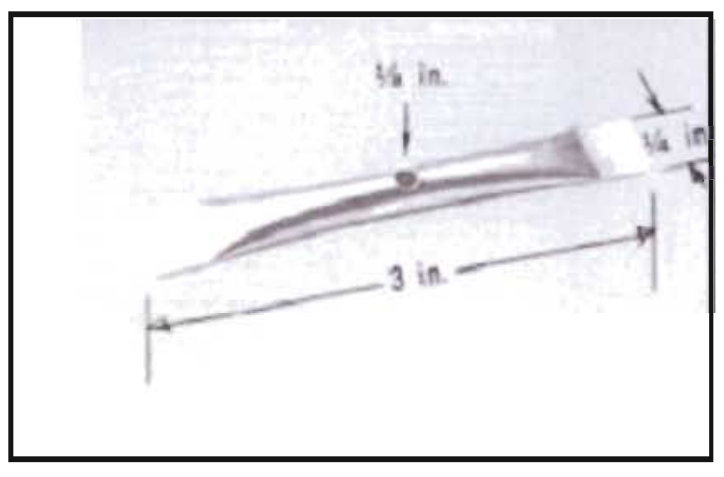

Figure 3.5: Tubular Boat ${ }^{23}$

four different boat setups. Each of the boats seen in figures 3.2 through 3.5 had weighed amounts of chalcogenide glass material placed in them and then wrapped with a fine tungsten mesh. ${ }^{21,22,23}$ The vacuum chamber pressure was brought down to $3.5 \times 10^{-5}$ torr and 100 amps of current run through each of the boats. Instead of slowly ramping up the current through the boat, the current was ramped up as fast as the machine could go without cracking the boat. The boat in figure 3.2 could not hold the chalcogenide glass. The boat in figure 3.3 could contain the chalcogenide glass, but could not hold enough to grow a thick enough film. While the Knudsen cell was big enough to hold enough material to grow a thick enough film and it could restrain the chalcogenide glass, the thermal evaporator could not produce enough current to heat the cell up enough to vaporize all the chalcogenide glass. The final boat in figure 3.5 was able to contain all the chalcogenide, hold enough of the material, and was small enough for the thermal evaporator to supply enough current to completely vaporize all of the chalcogenide glass. ${ }^{23}$ The tubular boat is nothing more than a tube with the ends collapsed and a hole drilled in the middle. The final process for growing a chalcogenide thin film is as follows: the boat seen in figure 3.5 is filled with a measured amount of chalcogenide 
glass, then wrapped with a fine tungsten mesh. The pressure in the thermal evaporator is brought down to $3.5 \times 10^{-5}$ torr and then 100 amps of current is applied through the boat and ramped up as fast as possible and stabilized until all the chalcogenide glass is evaporated.

In each case after deposition the thin film's thickness is measured and the slide stored. Metal thin films are packaged into a cardboard micro strip slide holder then stored in a vacuum box similar to the one used for the bulk chalcogenide glass. The slides with chalcogenide thin films are stored in a nitrogen box.

\subsubsection{Oblique deposition}

Oblique deposition is an experimental set up to characterize the thin films deposited at different angles. The inside of the beaker used as the sample holder shows 10 slides secured at three different angles and have three different glass strips masked off instead of one. Figure 3.6 is a picture of how the slides are secured inside of the

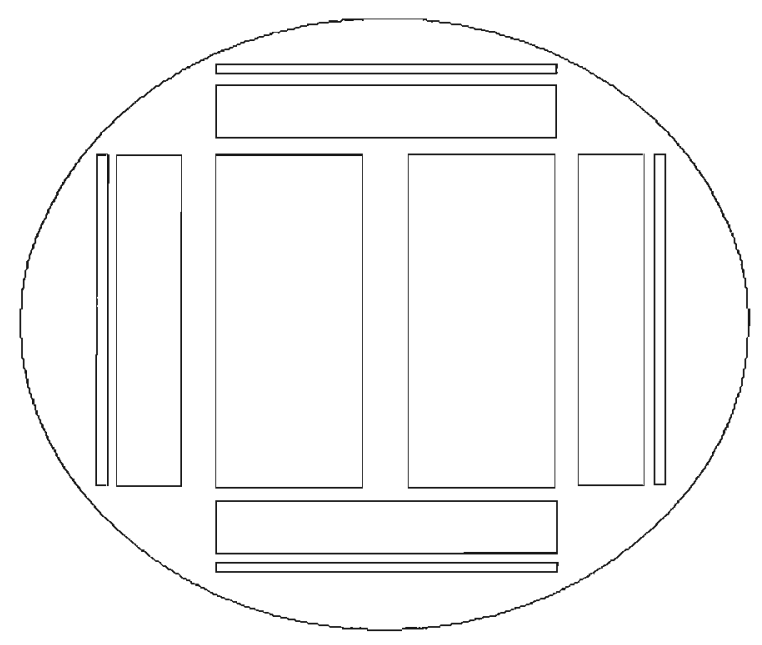

Top View

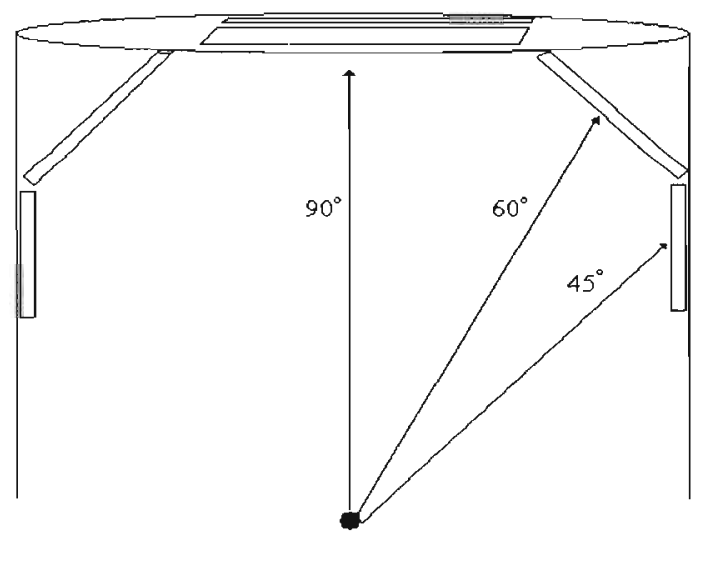

Side View

Figure 3.6: Layout of Glass Slides Inside Beaker 
sample holding beaker. Once the beaker is in place inside the vacuum chamber in the in the thermal evaporator, the vacuum chamber is evacuated to a pressure of $3.5 \times 10^{-5}$ torr and then 100 amps of current is applied through the boat and ramped up as fast as possible and stabilized until all the chalcogenide glass is evaporated. After the deposition all the slides are removed from the inside of the beaker and sliced into three so each sample has one of the masked off strips. Each sample is then labeled according to its position and angle on the inside of the beaker and the thickness of each of the thin film samples is measured. After the thickness is measured all the samples are stored in a nitrogen box for further processing and characterization.

\subsection{Thin Film Characterization}

Each of the thin films deposited in this experiment requires different analysis techniques for characterization of their various properties. For the two metal thin films made of aluminum and silver the only characterization done is the measurement of the film thickness using an Ambios XP-1 profilameter. The characteristics of thin films made of aluminum and silver is well understood, but what is not known is how well these films will adhere to Ag-Ge-S thin films. This is a topic for future research.

The characterization of the Ag-Ge-S thin films is more involved. Besides measuring the film thickness, the composition of the film is determined using Raman spectroscopy and scanning electron microscopy (SEM). Raman spectroscopy is used to determine both molecular and elemental composition of the thin film and the SEM is used to determine mole percentages and structure of the film. Once a chalcogenide film has been grown and processed, it is packaged in a cardboard microscope slide holder, 
placed in a plastic bag with a desiccant, and shipped off for Raman spectroscopy. All of the Raman spectroscopy done for this project was done by Dr. Sergey Mamedov at Jovin Yvon in New Jersey. Analysis of the chalcogenide glass thin films with SEM was conducted at two locations, Cal Poly State University San Luis Obispo Materials Engineering Department and the University of California in Santa Barbara.

\subsection{Thin Film Processing}

Initial Raman results of virgin chalcogenide glass thin films showed an abundance of elemental sulfur and a deficiency of silver. Samples from the oblique deposition experiment underwent two different treatments. One is photo-annealing of finished films using a UV light source. Based on work done at the Center for Solid State Electronics Research, Arizona State University, it has been shown that UV light can dissolve and redistribute silver in a chalcogenide glass film. ${ }^{25}$ The other treatment process is thermal annealing of the thin films at $150^{\circ} \mathrm{C}$ and $200^{\circ} \mathrm{C}$. Annealing should redistribute the sulfur, which has a boiling point of $112.8^{\circ} \mathrm{C}^{27}$

\subsubsection{Thermal Annealing}

For each of the annealing temperatures one 90,60 and 45 sample from the oblique deposition experiment is treated. Each of the samples is annealed in the Class 1000 clean room at Cal Poly campus in the Materials Engineering Department, with a hot plate in atmospheric conditions. One set of samples is annealed at $150 \mathrm{C}$ for one hour and another set is annealed at $200 \mathrm{C}$ for an hour. After processing the thickness of each thin film sample is measured using the profilometer and stored in a nitrogen box until analysis. 


\subsubsection{Photo Annealing}

Similar to annealing one 90,60 and 45 sample from the oblique deposition experiment is treated. Each of the chalcogenide glass thin films is placed in a Kepro BTX-200 UV Light Exposure Frame for a total of 40 min of exposure. The Kepro BTX200 UV Light Exposure Frame is an ultraviolet source primarily used for developing photoresist on printed circuit boards. After the samples are exposed, the film thickness is measured and then stored in a nitrogen box until analysis.

\subsection{Device Fabrication}

Figure 3.7 is a cross-section of a single device and figure 3.8 is a top view of 16 completed devices. The three thin film layers are deposited in the same thermal evaporator in two sessions. In between each session the device slide is stored in a

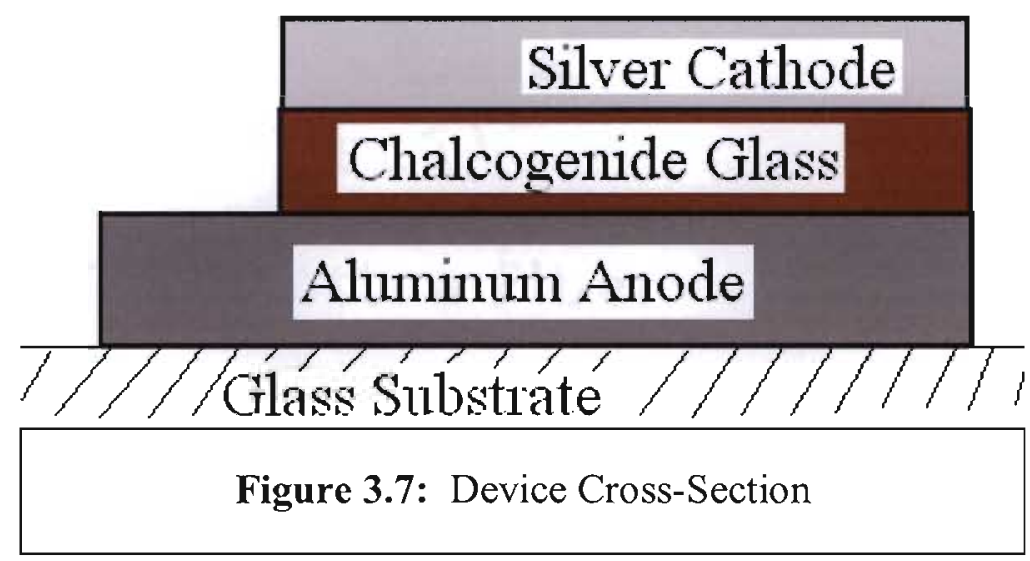


nitrogen box. Each set of devices starts off as two microscope slide. Both slides are cleaned with ethanol and/or acetone depending on what is available, and then left out for drying and blown clean using nitrogen. Using the following procedure six sets of devices were fabricated with each set having a different thickness of the chalcogenide thin film. Table 3.2 shows the different amount of glass used for each device set.

\begin{tabular}{|c|c|c|c|c|c|c|}
\hline Device Slides & A \& B & C \& D & E \& F & $G$ \& H & I \& J & K \& L \\
\hline Glass Amount (mg) & 16 & 30 & 60 & 120 & 24.5 & 10 \\
\hline
\end{tabular}

Table 3.2: Device Set Chalcogenide Glass Amounts

\subsubsection{Aluminum Anode}

The first layer of the device is the aluminum anode. The small tungsten wire basket filament seen in figure 3.9 is filled with $8 \mathrm{~cm}$ of 14 gauge aluminum wire and

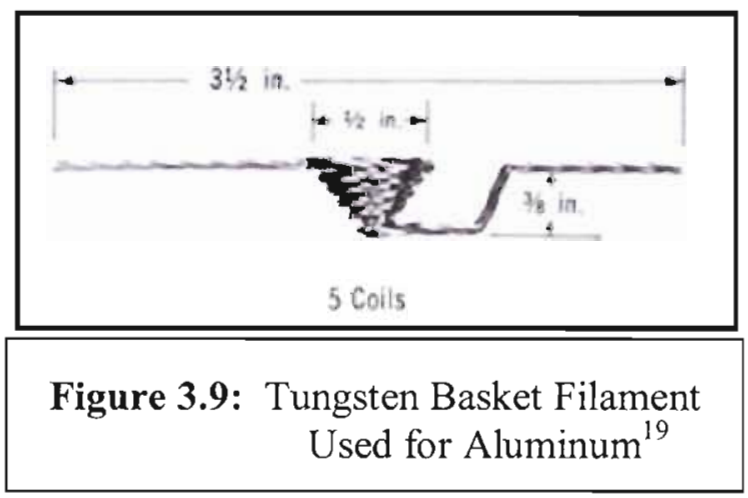

secured between one of the sets of electrodes. ${ }^{19}$ This amount of Al wire gives an aluminum layer thickness of around $1 \mu \mathrm{m}$. After setting up the filaments place the sample holding beaker over the electrodes and position shadow mask \#1 (see figure 3.10) 


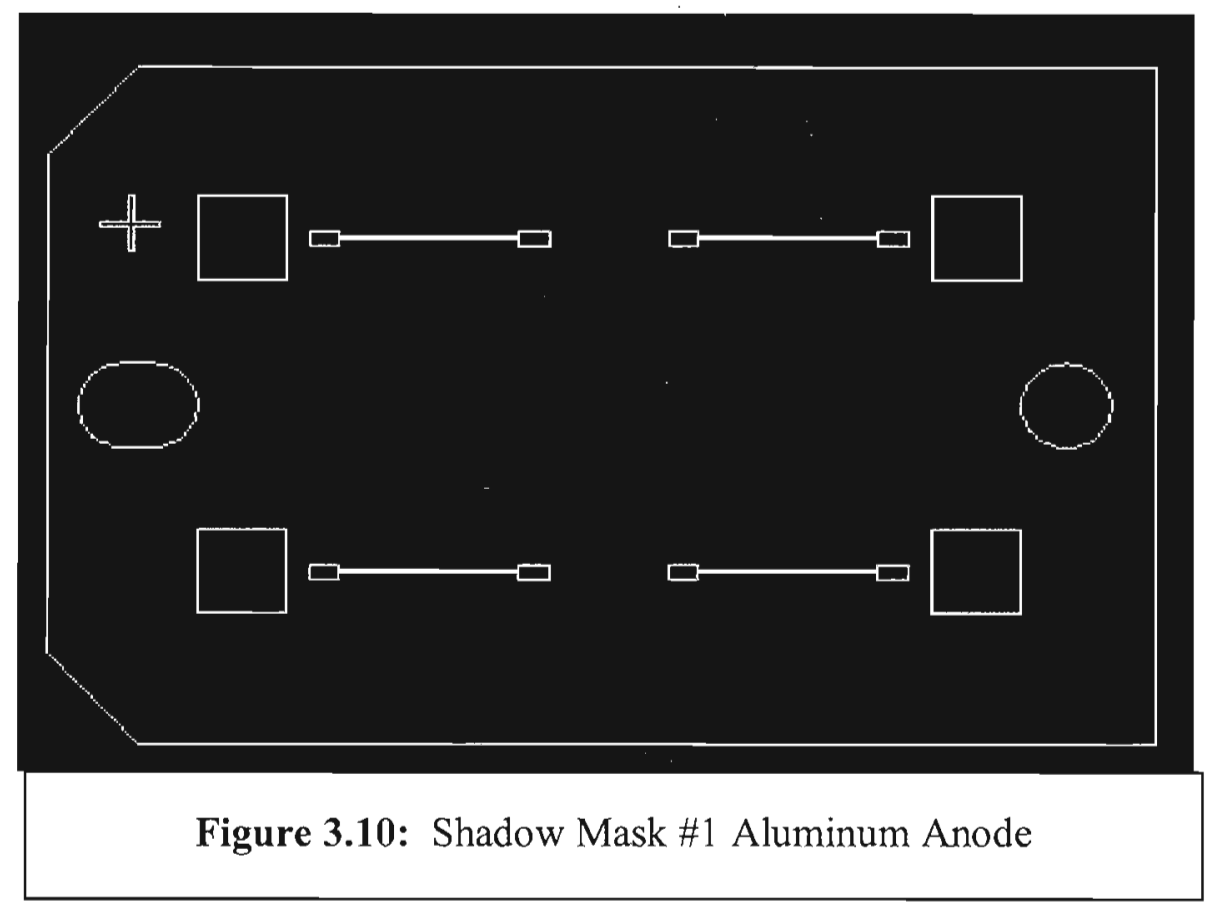

on the sample holder. (Note: the shadow masks used for this experiment were provided by Dr. Moodera of MIT.) Place the cleaned slides on top of shadow mask \#1, and align by eyesight, taping the slides in place on top of shadow mask \#1 using Kapton tape. Once the slides are secure, place the bell jar and safety cage on the base plate over the beaker. Evacuate the deposition chamber until the pressure reaches $3.5 \times 10^{-5}$ torr and evaporate the Aluminum with 70 Amps of current and 24 Volts for about 45 sec.. Vent the deposition chamber with atmosphere, remove the slides and store while setting up for layers 2 and 3. Figure 3.11 is a cross section of the device at this point.

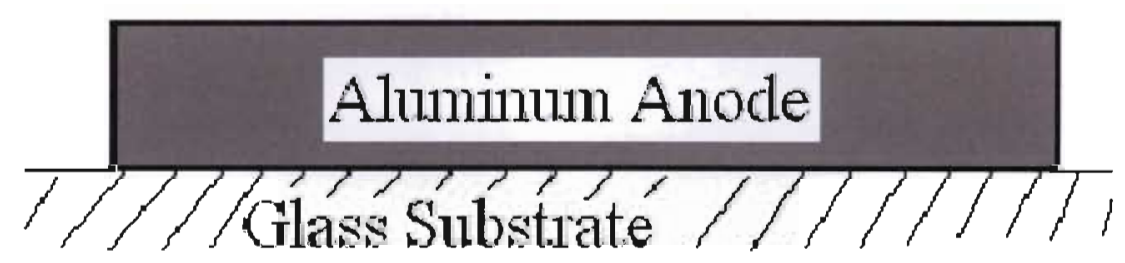

Figure 3.11: Device Cross Section, Aluminum Anode 


\subsubsection{Chalcogenide Glass Thin Film}

The $2^{\text {nd }}$ and $3^{\text {rd }}$ layer, the chalcogenide glass and silver layer, are deposited during one pump down of the deposition chamber and use the same shadow mask. For the $2^{\text {nd }}$ layer the tungsten boat seen in figure 3.12 is filled with different amounts of

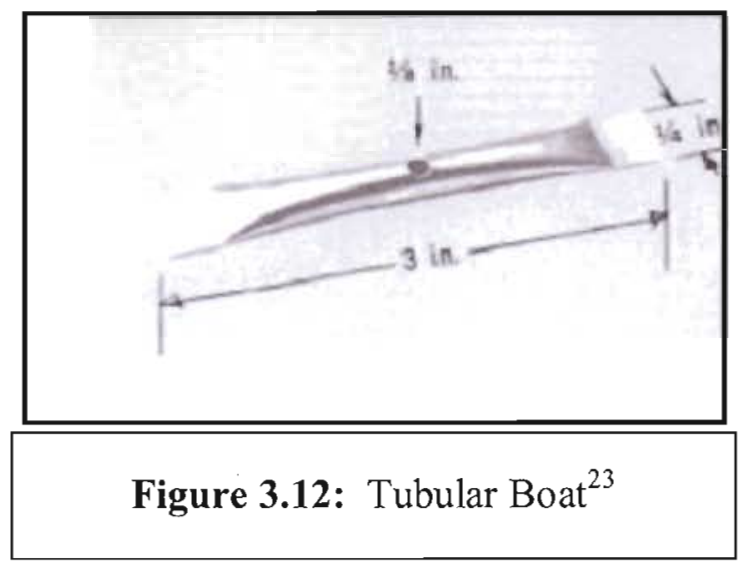

chalcogenide glass, depending on the thickness of the layer desired, and wrapped with a thin tungsten mesh and placed across one set of electrodes. ${ }^{23}$ Also the boat containing the

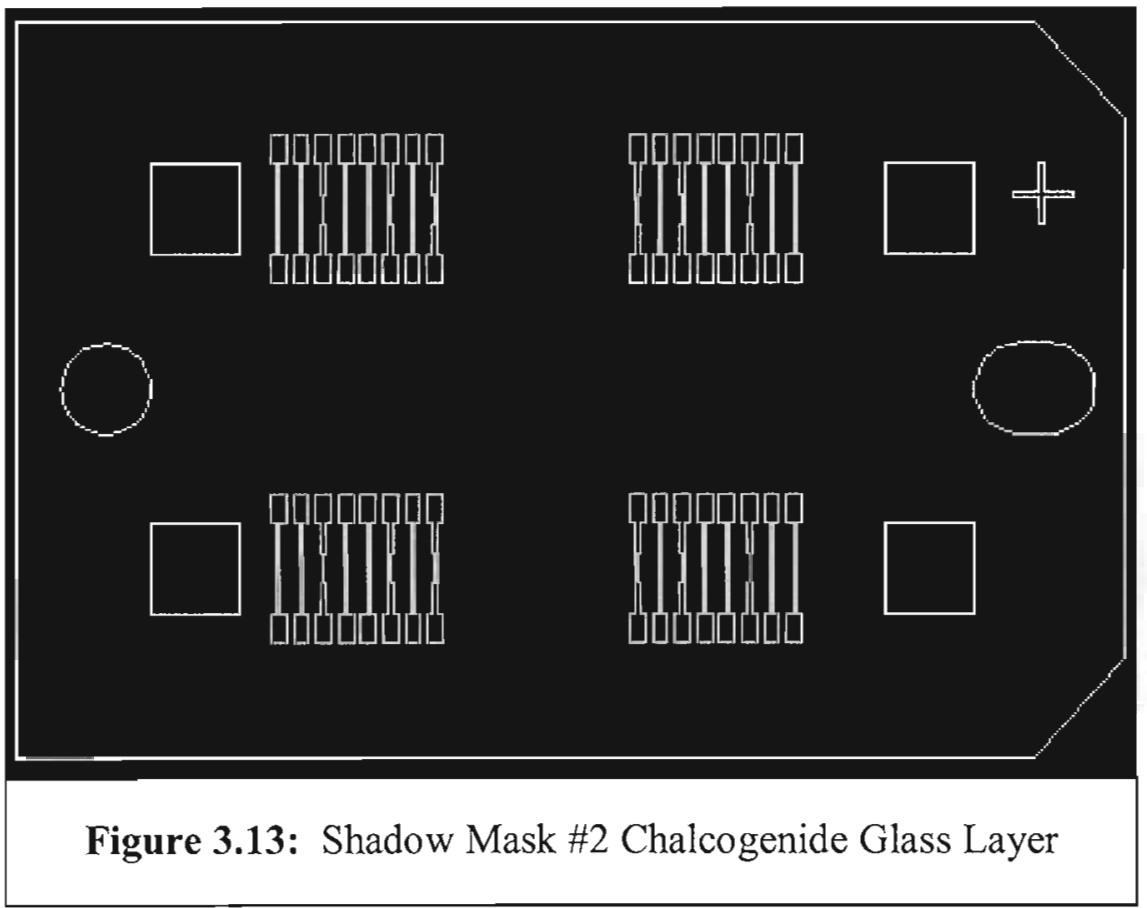


silver is placed across the $2^{\text {nd }}$ set of electrodes. Once both boats are set up the sample holding beaker is placed over the electrodes and shadow mask \#2 is aligned with the holes in the sample holder and taped down with Kapton tape (see figure3.13).

Align the glass slides with already have the aluminum layer with shadow mask \#2 by eye and fasten with Kapton tape. Evacuate the deposition chamber until the pressure reaches $3.5 \times 10^{-5}$ torr. and evaporate the chalcogenide glass with $100 \mathrm{Amps}$ of current and 24 Volts for about $45 \mathrm{sec}$. Figure 3.14 is a cross section of the device after the layer of chalcogenide glass is deposited on the microscope slide.

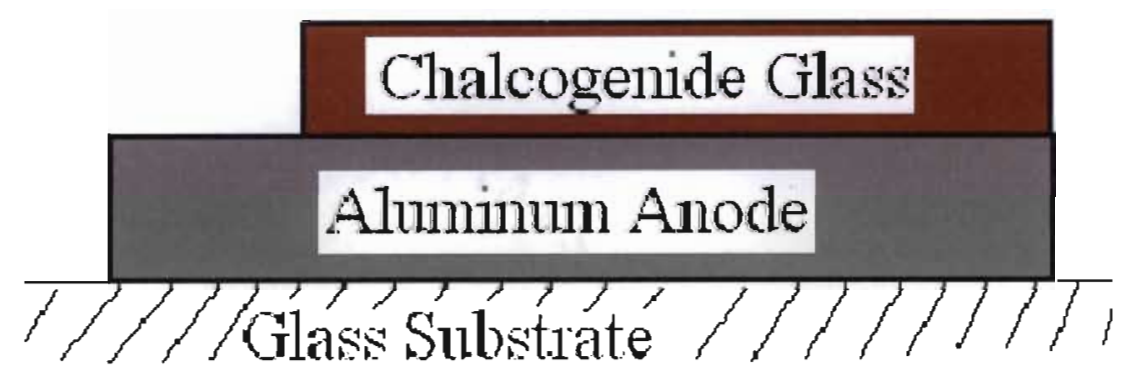

Figure 3.14: Device Cross Section, Aluminum Anode and Chalcogenide Glass Thin Film

\subsubsection{Silver Cathode}

The $3^{\text {rd }}$ layer uses the boat seen in figure 3.15. It is made of molybdenum and filled with $10 \mathrm{~cm}$ of 14 gauge silver wire. ${ }^{20}$ Right after the chalcogenide layer is deposited, pump down the deposition chamber back down to a pressure of $3.5 \times 10^{-5}$ torr and evaporate the Silver with 80 Amps of current and 24 Volts. Vent until atmospheric pressure is reached and remove slides. Store in a nitrogen cabinet until the device can be 


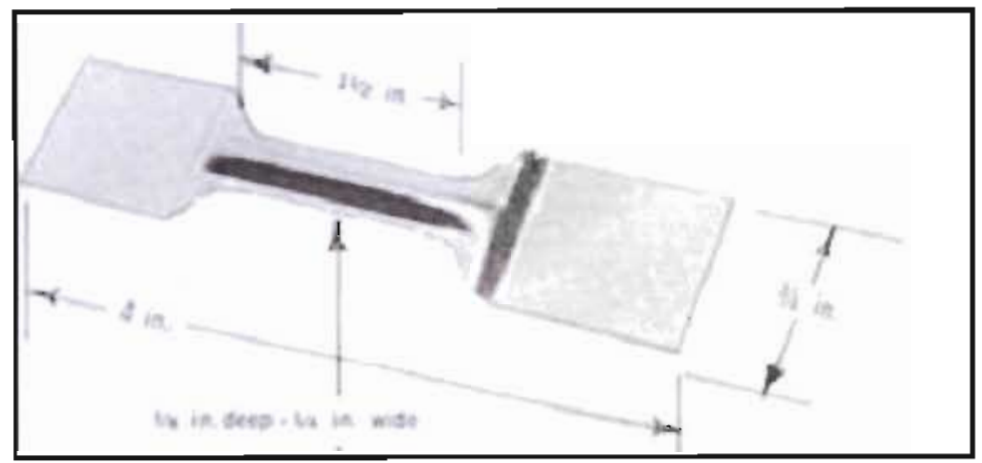

Figure 3.15: Molybdenum Boat Used for Silver ${ }^{20}$

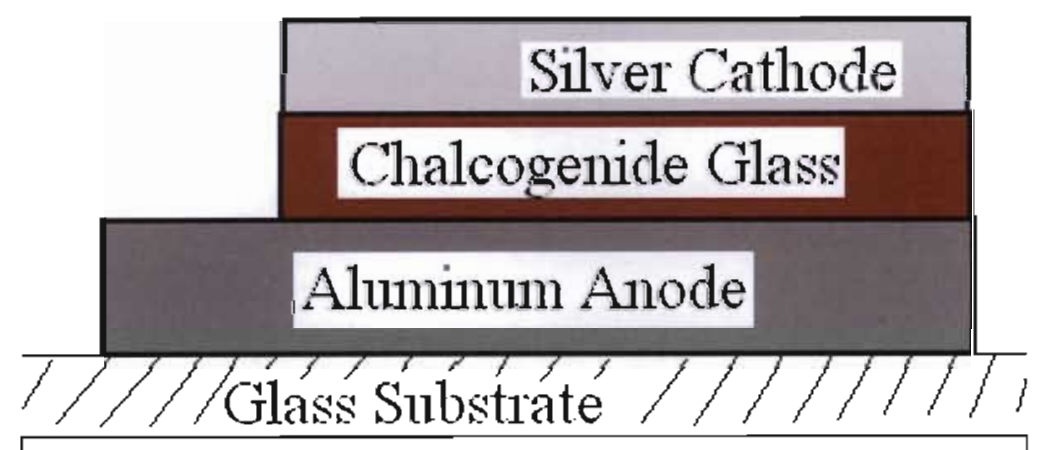

Figure 3.16: Completed Device Cross Section

tested. Figure 3.16 is cross section of a completed device

\subsection{Device Testing}

Using a Signatone S-250 test bench and Keithley 2400 Source Meter seen in

figure 3.17 , the first slide was tested completely manually. The slide was secure with a vacuum and the testing probes attached; a voltage was applied, then the current drawn recorded. The voltage applied starts at zero and increased until 1.0 Volt and then 
decreased until -1.0 Volts, then back to zero volts. This process took about 10 minutes, with two people for only one device cycle. One person recorded the results, the other adjusted the voltage as necessary, then called out the current value after it had stabilized. Three cycles/device X $10 \mathrm{~min} /$ cycle X 16 devices/slide $=480 \mathrm{~min}$ per slide.

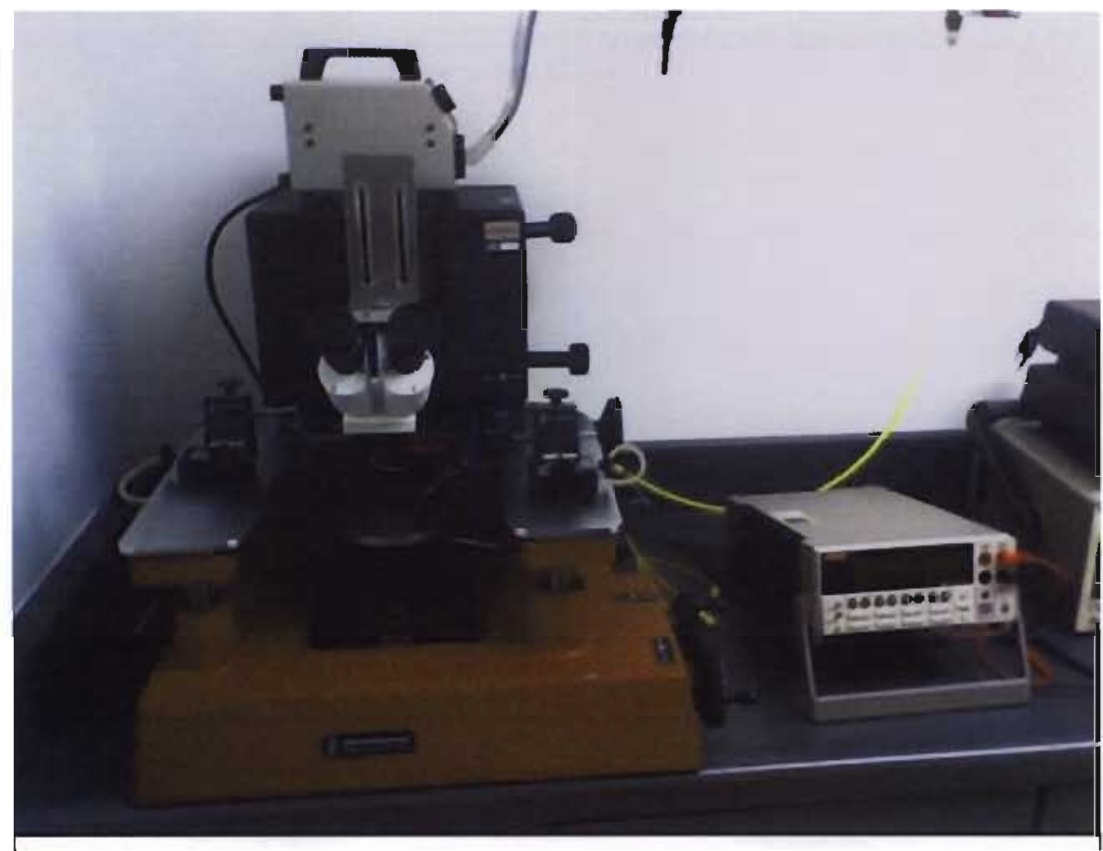

Figure 3.17: Signatone S-250 Test Bench and Keithley 2400 Source Meter

In an effort to speed up the testing of devices, Carter De Leo, a member of the project group, wrote two programs: one that applied a voltage from zero to 1.0 volts then -1.8 Volts then back to zero volts for three cycles and recorded the current; and then another device metric program that recorded device functionality, write current, erase current and turn on voltage. Figure 3.18 is a screen shot of the testing program user interface. This reduced the time to test one device from around $1 / 2$ hour to only five minutes. Each individual device was still connected manually but now the testing was 


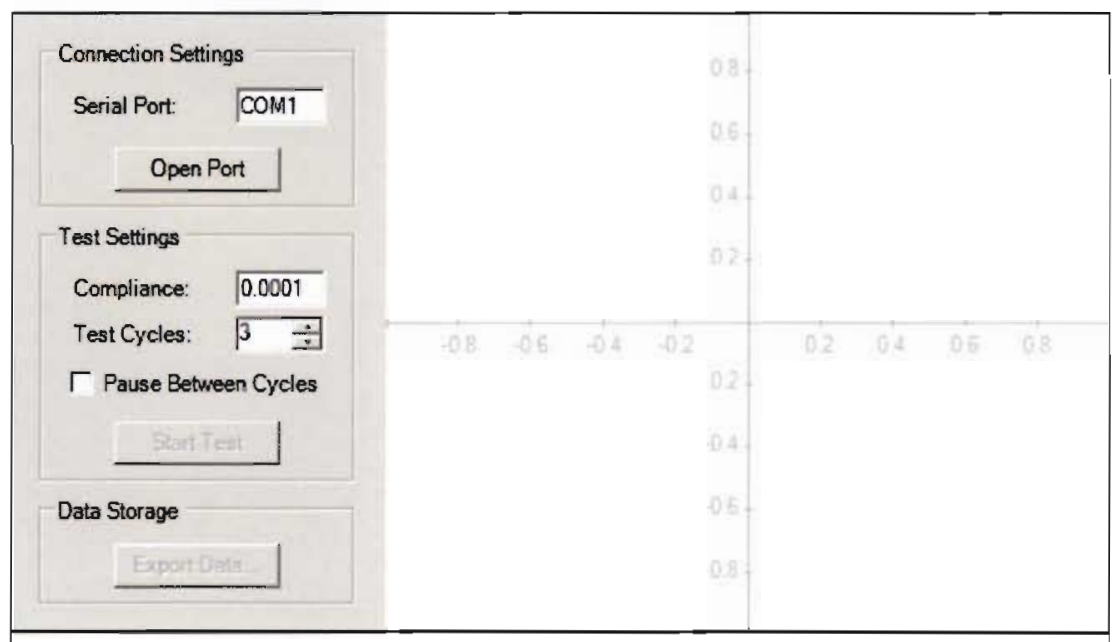

Figure 3.18: Device Testing Interface

automated, removing the human error from measuring and recording results. 


\section{Chapter 4: Results and Discussion}

\subsection{Thin Film and Bulk Raman Results Comparison}

Figures 4.1 and 4.2 show the Raman results for two Ag-Ge-S thin films of two different compositions. One is $\left[\mathrm{Ag}_{0.1}\left(\mathrm{Ge}_{.75} \mathrm{~S}_{.25}\right)_{0.9}\right]$ or $10 \%$ silver mixture, the other is $\left[\mathrm{Ag}_{0.2}\left(\mathrm{Ge}_{75} \mathrm{~S}_{25}\right)_{0.8}\right]$ or $20 \%$ silver mixture. Figure 4.3 is the Raman Results for bulk AgGe-S glass of compositions $[\operatorname{Agx}(\mathrm{Ge} .75 \mathrm{~S} .25)](\mathrm{x}=0,0.1,0.2,0.3,0.4$ and 0.5$)$. By comparing Raman results in figures 4.1 and 4.2 with figure 4.3 , one can clearly observe that the Raman lineshapes of the Ag-Ge-S thin films roughly agree with those of the

corresponding bulk Ag-Ge-S lineshapes. ${ }^{24}$ Besides this agreement, we observe two peaks at $210(\mathrm{~cm}-1)$ and $470(\mathrm{~cm}-1)$, respectively, that are not observed in the bulk Ag-Ge-S bulk samples. These two peaks are signatures of elemental $\mathrm{S}_{8}$ crown structure.

A more thorough comparison of the Raman results require the use of a software program Peakfit. With this software the Raman results for both the thin film and bulk chalcogenide glass samples can be deconvoluted into the individual Gaussian peaks that correspond to certain molecular structures. Figures 4.4 and 4.5 show the deconvolutions of the $20 \%$ bulk Ag-Ge-S glass and the $20 \%$ Ag-Ge-S glass thin film Raman results respectively. ${ }^{24}$ The primary molecular structures of the bulk Ag-Ge-S glass shown in figure 4.4 are Qm ( $m=1,2,3$ or 4, notice Q4 is actually CS Ge-S tetrahedral) and ES Ge-S tetrahedra modes. $Q_{m}$ is known as thiogermanate units. m represents the number of bridging $\mathrm{S}$ in the Ge-S tetrahedral, i.e. (4-m) silver atom attaching to $\mathrm{S}$ making it nonbridging $\mathrm{S}$. For example, the $\mathrm{Q}_{3}$ mode has 3 bridging $\mathrm{S}$ and one terminating $\mathrm{S}$ attaching to silver. The Comer sharing (Q4 mode) and Edge sharing Ge-S modes both correspond to Germanium Sulfur tetrahedral. The difference between corner sharing and edge 


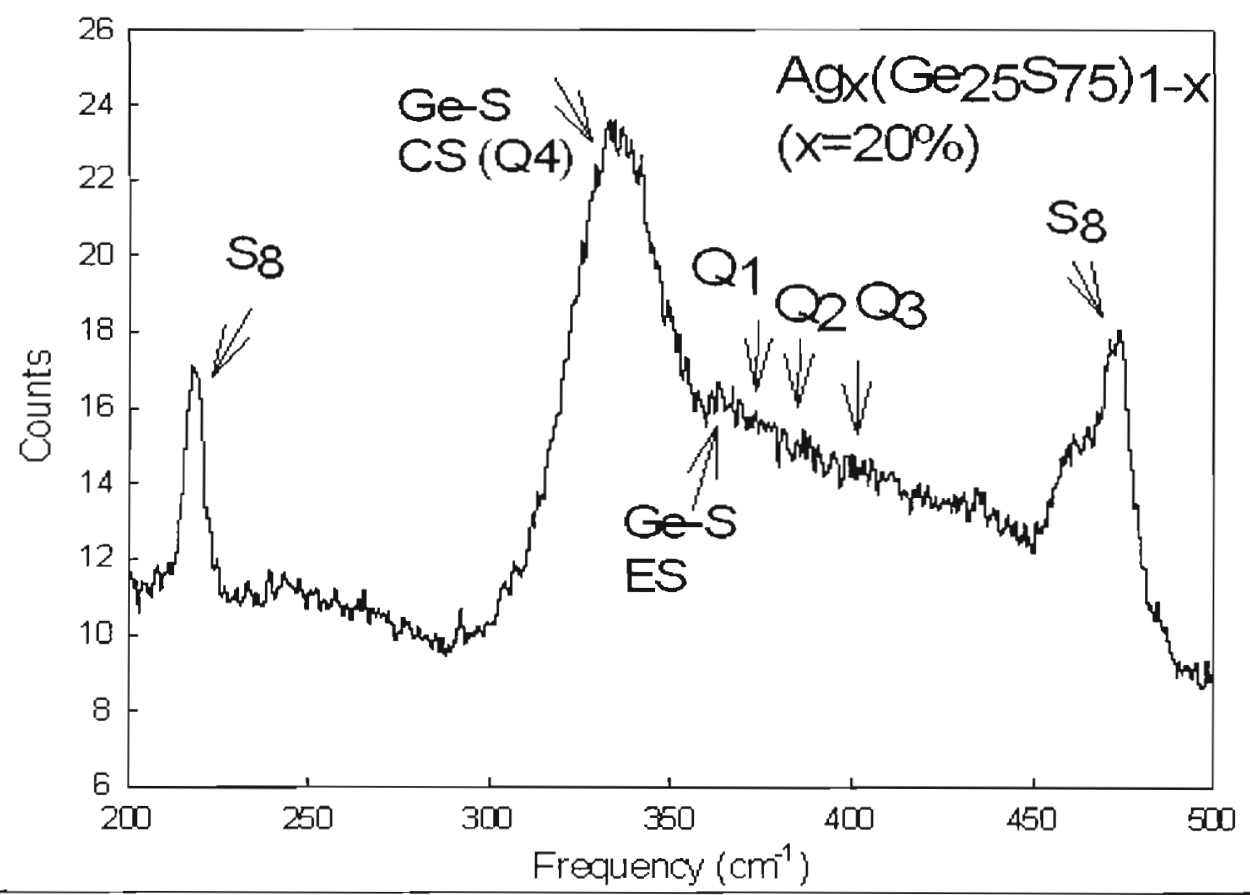

Figure 4.1: Raman Results for Ag-Ge-S Glass Thin Film (10\% Silver)

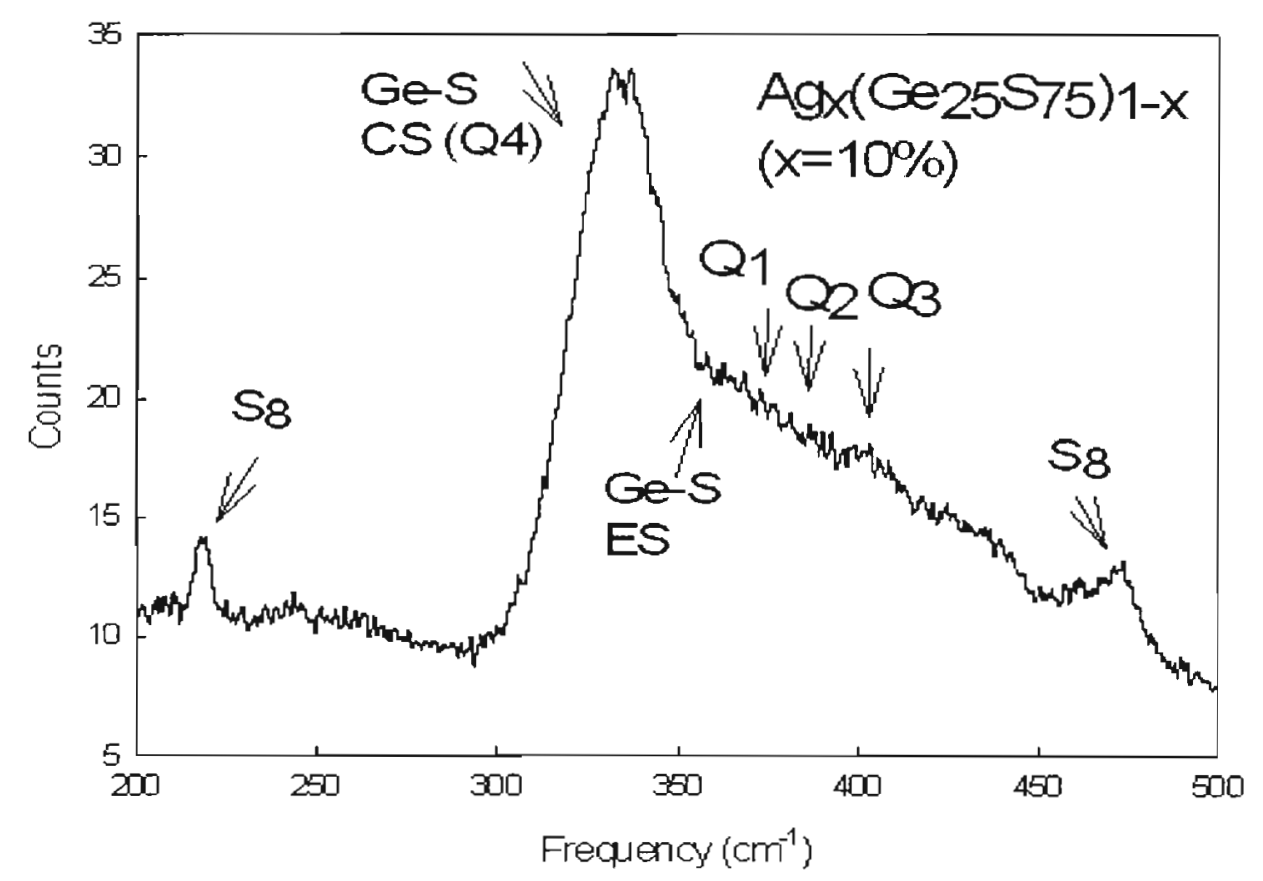

Figure 4.2: Raman Results for Ag-Ge-S Glass Thin Film (20\% Silver) 


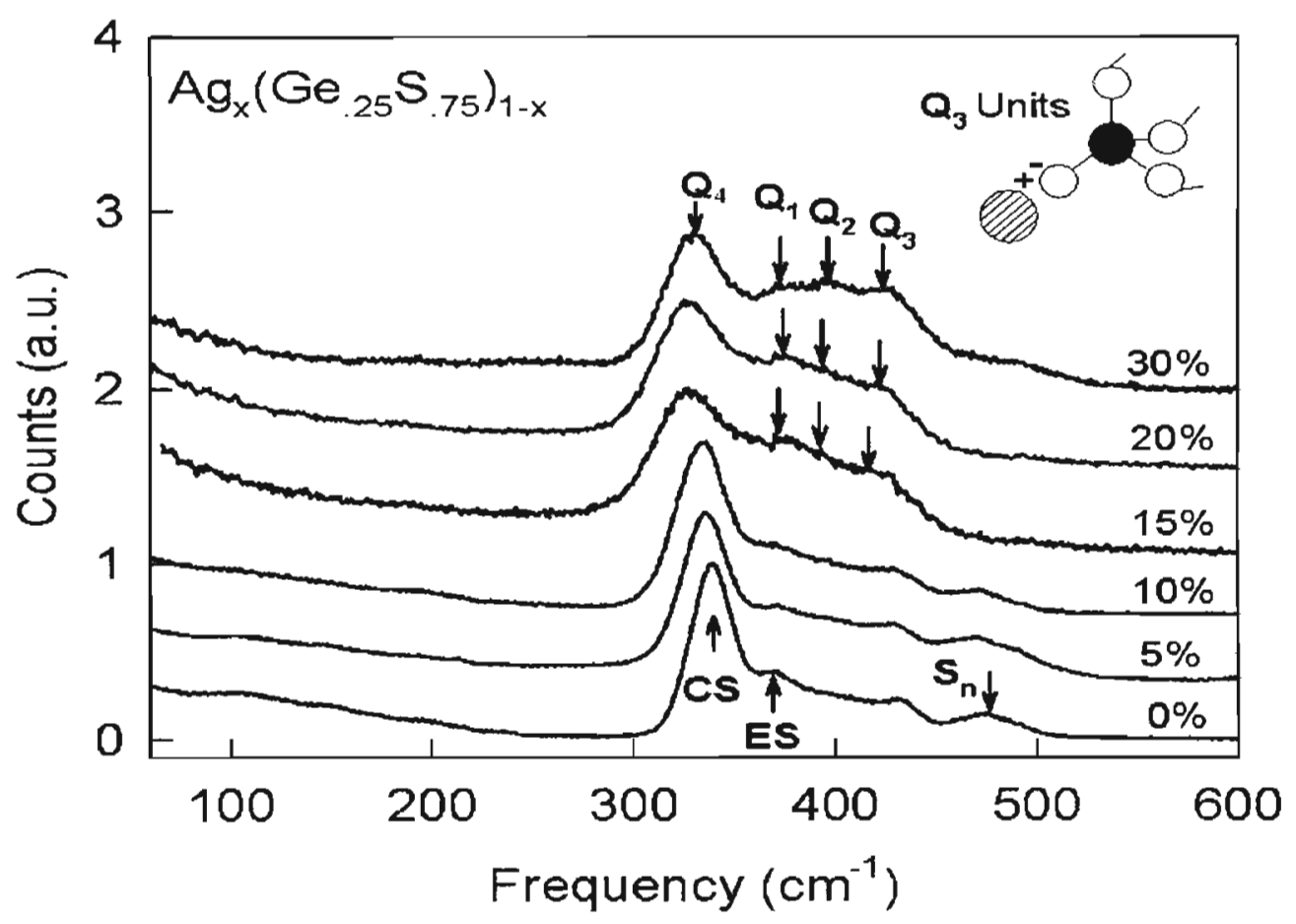

Figure 4.3: Raman Results for Bulk Ag-Ge-S Glass ${ }^{24}$

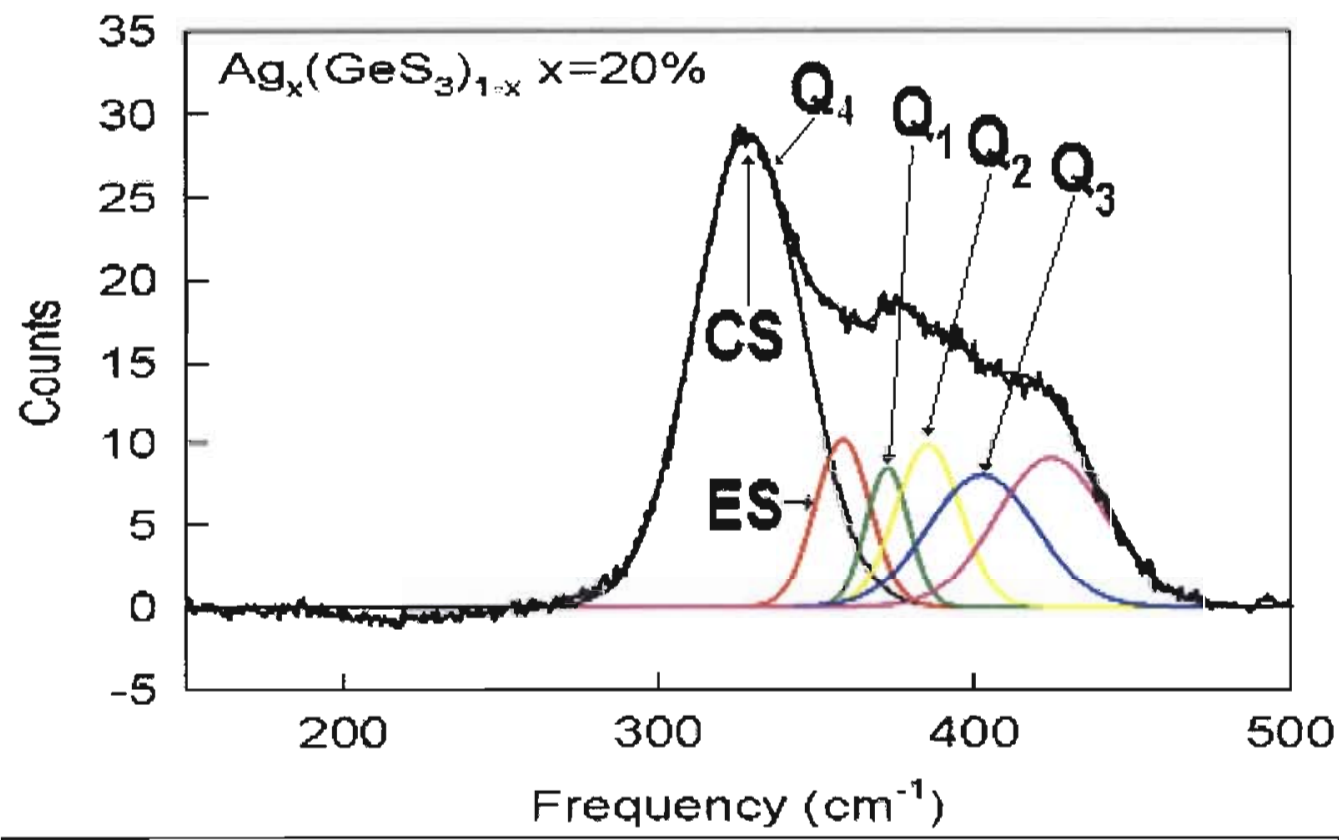

Figure 4.4: Raman Results Deconvolution for Bulk Ag-Ge-S (20\% silver) ${ }^{24}$ 


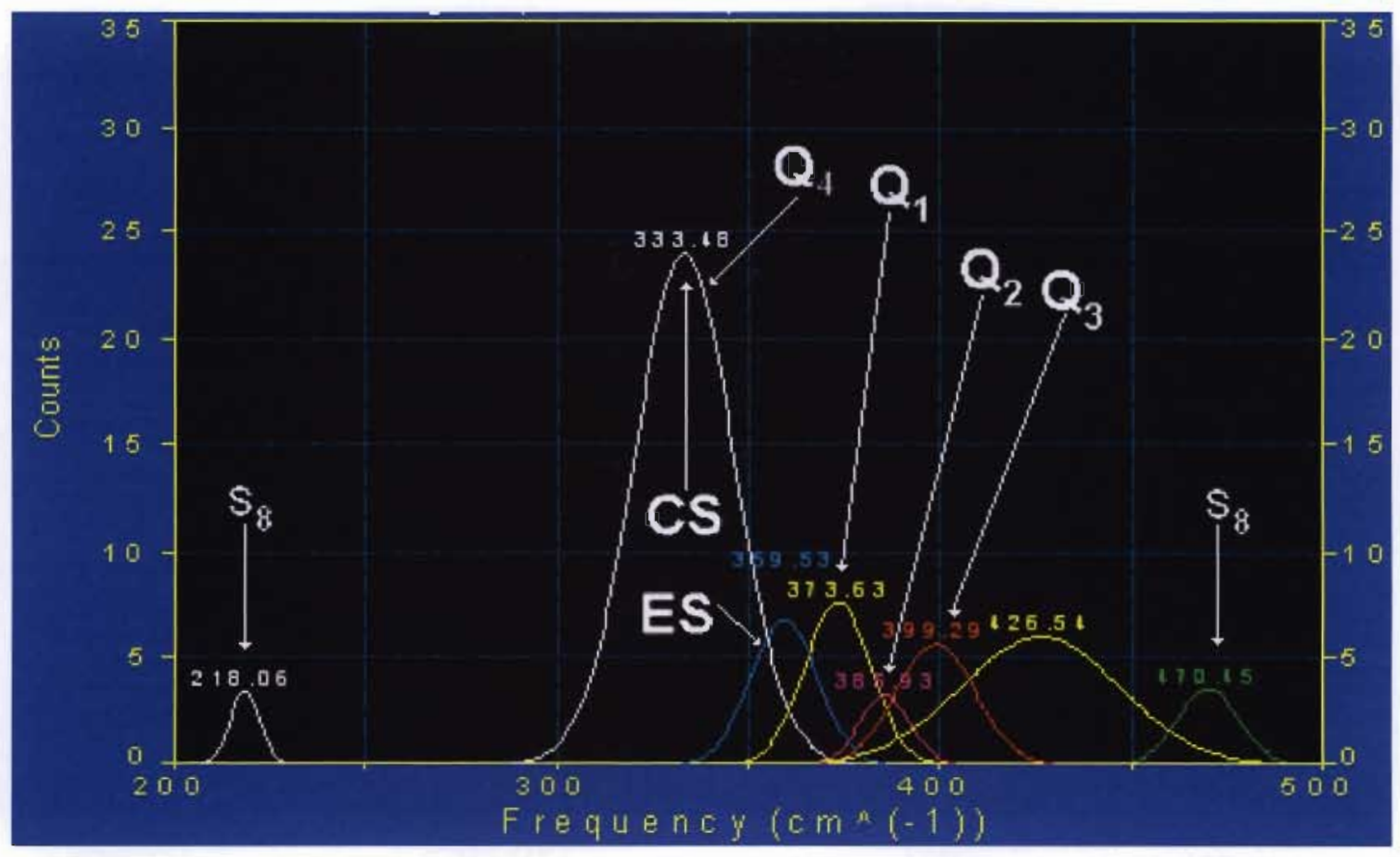

Figure 4.5: Raman Results Deconvolution for Thin Film Ag-Ge-S (20\% silver)

sharing modes is how this structure connects with others. The corner sharing mode only shares one Sulfur with the neighboring tetrahedral, while the edge sharing mode shares two Sulfurs with the neighboring tetrahedral.

When comparing the thin film Ag-Ge-S glass to the bulk Ag-Ge-S glass it can be seen that both samples have CS and ES germanium to sulfurs modes. For the bulk AgGe-S glass the CS peak is at $330\left(\mathrm{~cm}^{-1}\right)$ and for the thin film Ag-Ge-S glass the peak is at $333\left(\mathrm{~cm}^{-1}\right)$. A similar trend is seen in the ES modes where the bulk material has a peak at $360\left(\mathrm{~cm}^{-1}\right)$ and the thin film has a peak at 359.53 , almost exactly the same location. In addition, the thiogermanate peaks also match up well. See table 4.1 for results.

The only substantial difference between the Ag-Ge-S thin film glass and the bulk AG-Ge-S glass is two elemental sulfur peaks found in the thin film located at 210 


\begin{tabular}{|c|c|c|}
\hline Mode & \multicolumn{2}{|c|}{ Frequency (cm-1) } \\
\hline & $\begin{array}{c}\text { Chalcogenide Glass } \\
\text { Thin Film }\end{array}$ & $\begin{array}{c}\text { Bulk } \\
\text { Chalcogenide Glass }\end{array}$ \\
\hline $\mathrm{Q} 1$ & 373.63 & 370 \\
\hline $\mathrm{Q} 2$ & 385.93 & 385 \\
\hline $\mathrm{Q} 3$ & 399.29 & 400 \\
\hline $\mathrm{Q} 4$ (CS) & 333 & 330 \\
\hline $\mathrm{ES}$ & 359.53 & 360 \\
\hline \multicolumn{3}{|c|}{ Table 4.1: Comparison of Bulk Ag-Ge-S Glass and } \\
Ag-Ge-S Thin Film Glass Modes
\end{tabular}

$\left(\mathrm{cm}^{-1}\right)$ and $470\left(\mathrm{~cm}^{-1}\right)$. The presence of elemental sulfur is because of the different heat of vaporization for each of the respective elements in the Ag-Ge-S glass thin film. As is seen in table 4.2 , the heat of vaporization of sulfur is about a $1 / 5$ of germanium and

\begin{tabular}{|c|c|}
\hline Element & Heat of Vaporization \\
\hline Sulfur & $45 \mathrm{~kJ} / \mathrm{mol}$ \\
\hline Germanium & $250.58 \mathrm{~kJ} / \mathrm{mol}$ \\
\hline Silver & $334 \mathrm{~kJ} / \mathrm{mol}$ \\
\hline \multicolumn{2}{|c|}{ Table 4.2: Heat of Vaporization } \\
\hline
\end{tabular}

a 1/7 of silver. ${ }^{16,17,18}$ The sulfur evaporates out of the material before the silver or germanium and some of it collects as small amounts of elemental sulfur on the substrate.

The difference in the heat of vaporization between the elements is also the reason the material was ejected from the boat during evaporation. The Sulfur would vaporize and form small pockets of Sulfur gas inside the Ag-Ge-S bulk glass. When the pressure 
got great enough it would erupt, and pop pieces of the bulk Ag-Ge-S out of the boat. This abundance of sulfur also causes the Ag-Ge-S thin films to be a little Ag deficient. In conclusion while the Ag-Ge-S glass thin films closely resemble their bulk Ag-Ge-S glass counterpart, Ag-Ge-S thin films grown in a thermal evaporator tend to be Sulfur rich and Ag deficient. The thermal evaporator also tends to make less homogeneous AgGe-S glass thin films. Either this process needs further revision or an alternative method of growing Ag-Ge-S thin films (such as magnetron sputtering) should be used.

\subsection{SEM Results}

Along with Raman spectroscopy the Ag-Ge-S glass thin film was analyzed with Fei Quanta 200 SEM as well. Figure 4.6 is a SEM picture of 20\% silver Ag-Ge-S

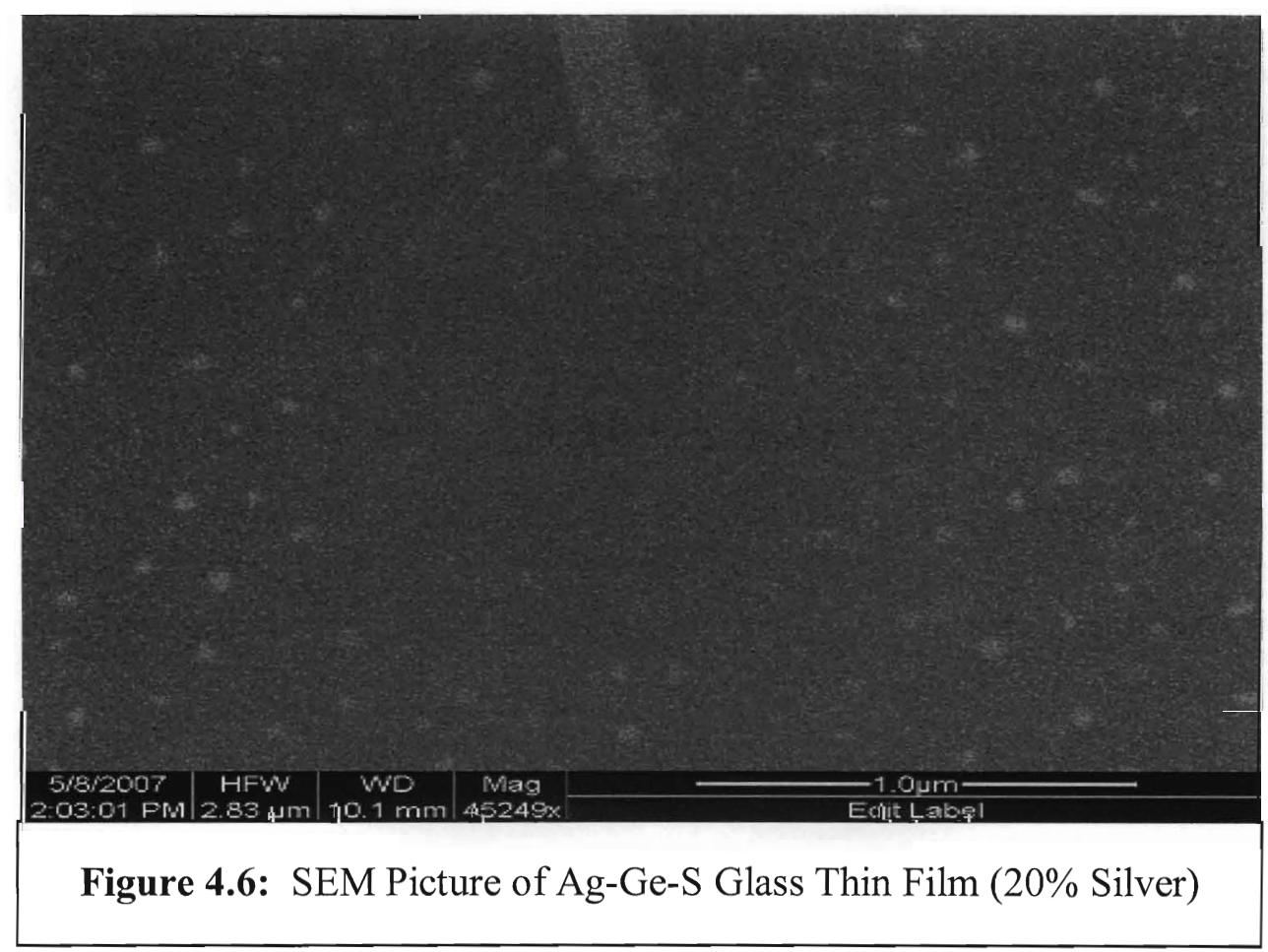

glass thin film at $45249 \mathrm{x}$ magnification with $40 \mathrm{KeV}$ beam in a $1 \times 10-6$ torr vacuum. The 
small light grey dots scattered over the dark grey background are approximately $50 \mathrm{~nm}$ in diameter. These dots are Silver rich phases (probably $\mathrm{Ag}_{2} \mathrm{~S}$ ) and have a higher conductivity than the background. ${ }^{26}$ This is confirmed by letting the SEM beam sit in the same spot for a moment. Notice that the center of the picture in figure 4.6 is devoid of the little grey dots. This is because highly mobile Silver is migrating away from the bombarding electron beam over time. This is evidence of the switching mechanism the device is based on.

\subsection{Oblique Results}

\subsubsection{Thickness}

Measuring the film thickness of the Ag-Ge-S glass thin films deposited in the oblique deposition experiment revealed that as the distance from the boat decreased, the the thickness of the film increased. In figures $4.7-4.9$, there are profilometer readouts

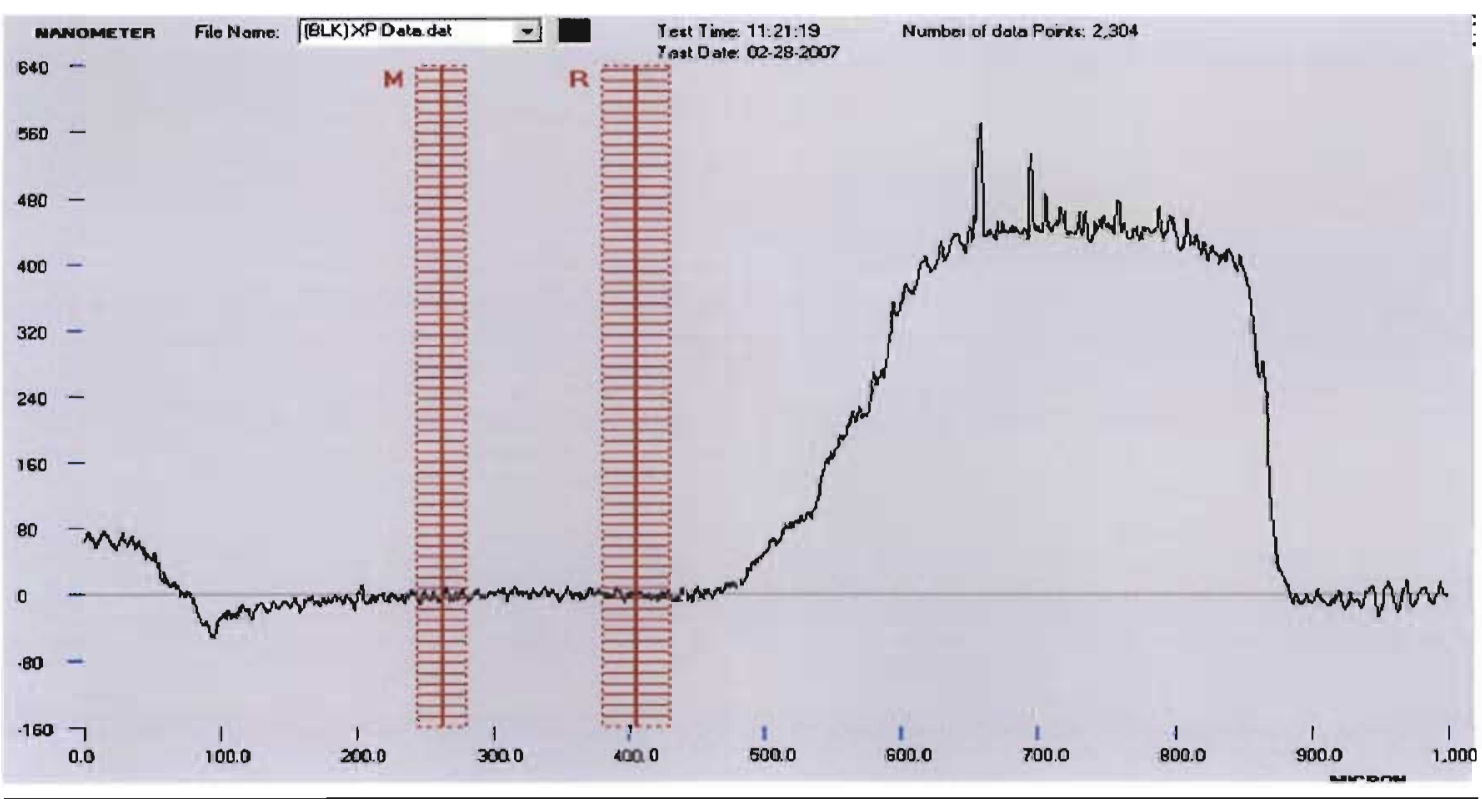

Figure 4.7: $90^{\circ}$ Thin Film, 480 nm thick 


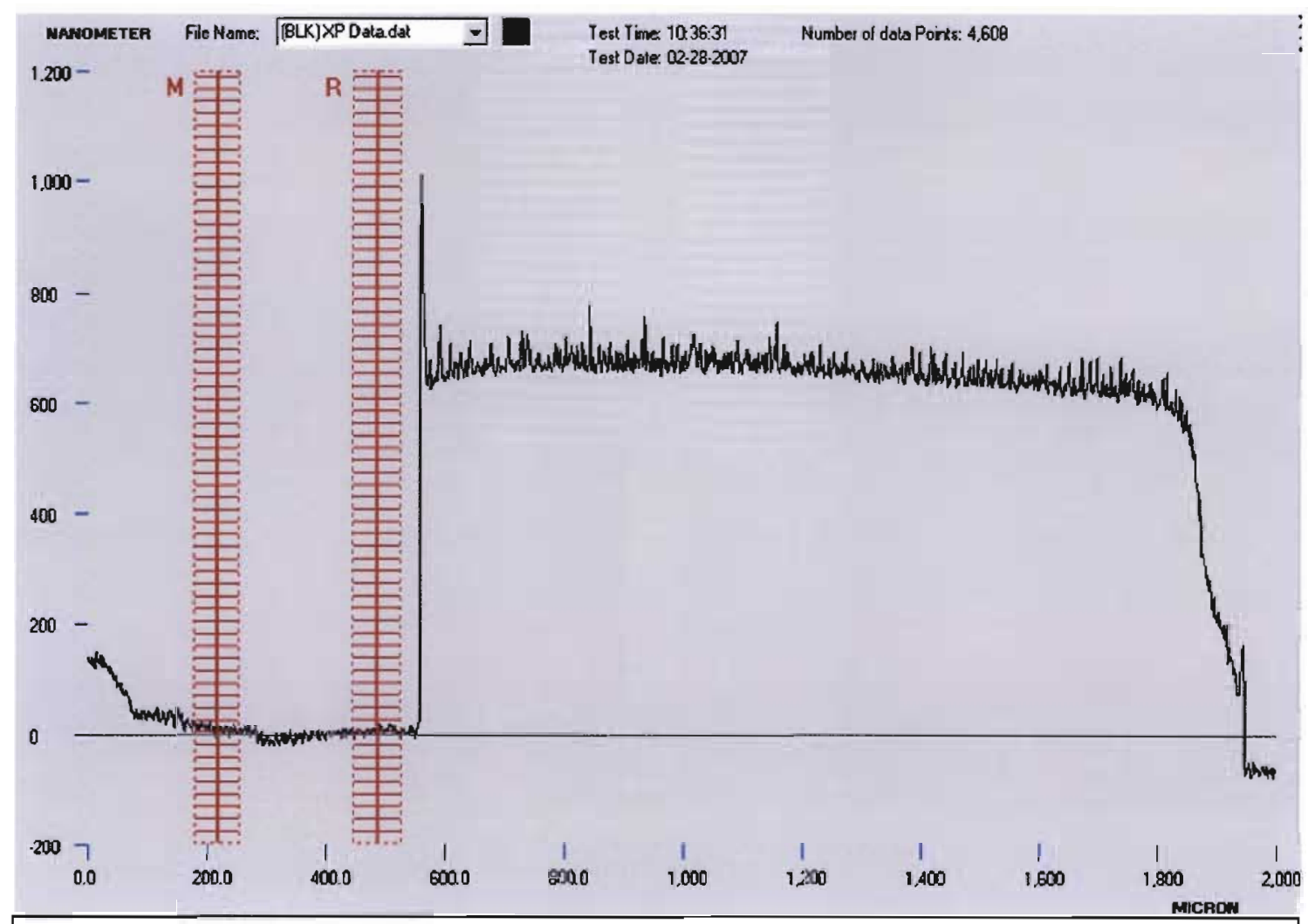

Figure 4.8: $60^{\circ}$ Thin Flim, $650 \mathrm{~nm}$ Thick

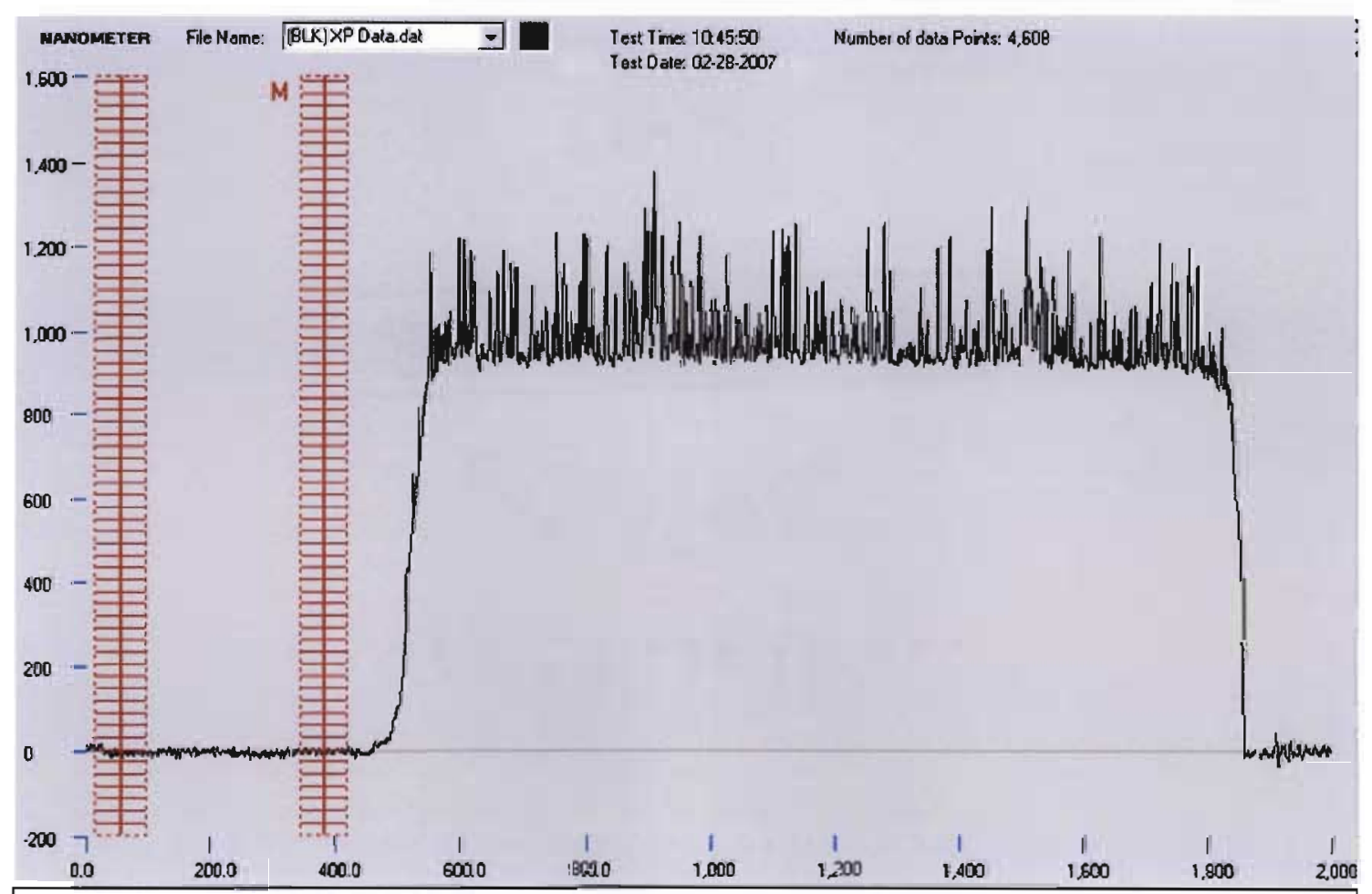

Figure 4.9: $45^{\circ}$ Thin Flim, $900 \mathrm{~nm}$ Thick 
for $90^{\circ}, 60^{\circ}$ and $45^{\circ}$ sample respectively. The $90^{\circ}$ sample is $480 \mathrm{~nm}$, the $60^{\circ}$ sample is $650 \mathrm{~nm}$ thick and the $45^{\circ}$ samples $900 \mathrm{~nm}$ thick, a total difference in thickness of $420 \mathrm{~nm}$. Clearly the closer the substrate is to the material being evaporated, the thicker the film. These results lead to a solution to one of the problems with growing the Ag-Ge-S glass thin films. Growing a Ag-Ge-S glass thin film requires around $500 \mathrm{mg}$ of material to get a thin film with a thickness of around $1 \mu \mathrm{m} .500 \mathrm{mg}$ is a significant portion of the bulk chalcogenide material available. By using the shorter beaker (figure 4.10), the amount of Ag-Ge-S chalcogenide glass needed to grow films

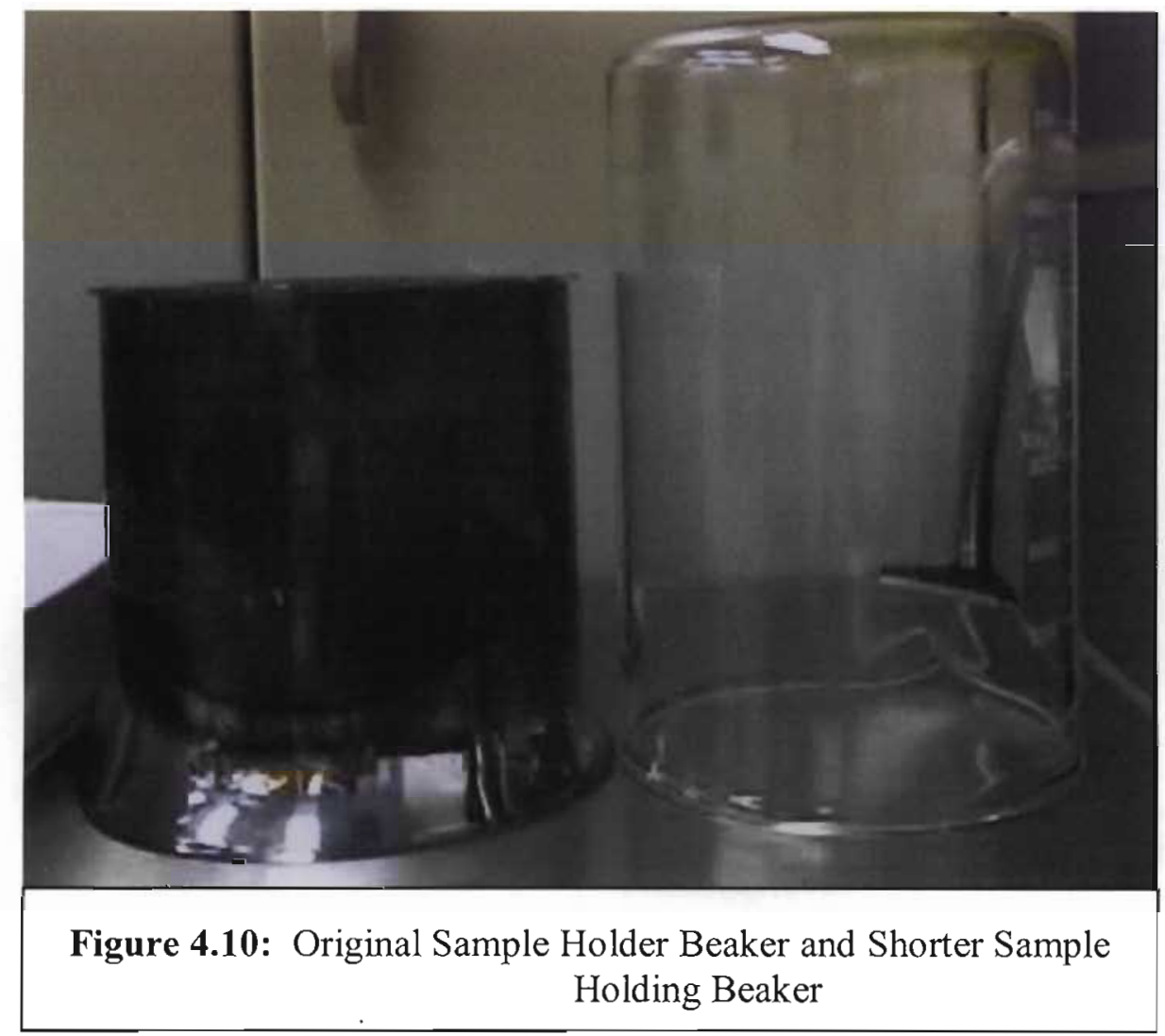

with the same thickness is reduced by a factor of 2 . Using the shorter beaker $230 \mathrm{mg}$ of Ag-Ge-S bulk glass could deposit around a $1 \mu \mathrm{m}$ thick thin film. Increasing the thickness 
of the thin was a must for SEM and Raman spectroscopy to function properly; the sample needed a minimum thickness of about $1 \mu \mathrm{m}$.

\subsubsection{Raman Results for Virgin Samples}

Figure 4.11 is a graph of the Raman results of Ag-Ge-S thin films deposited

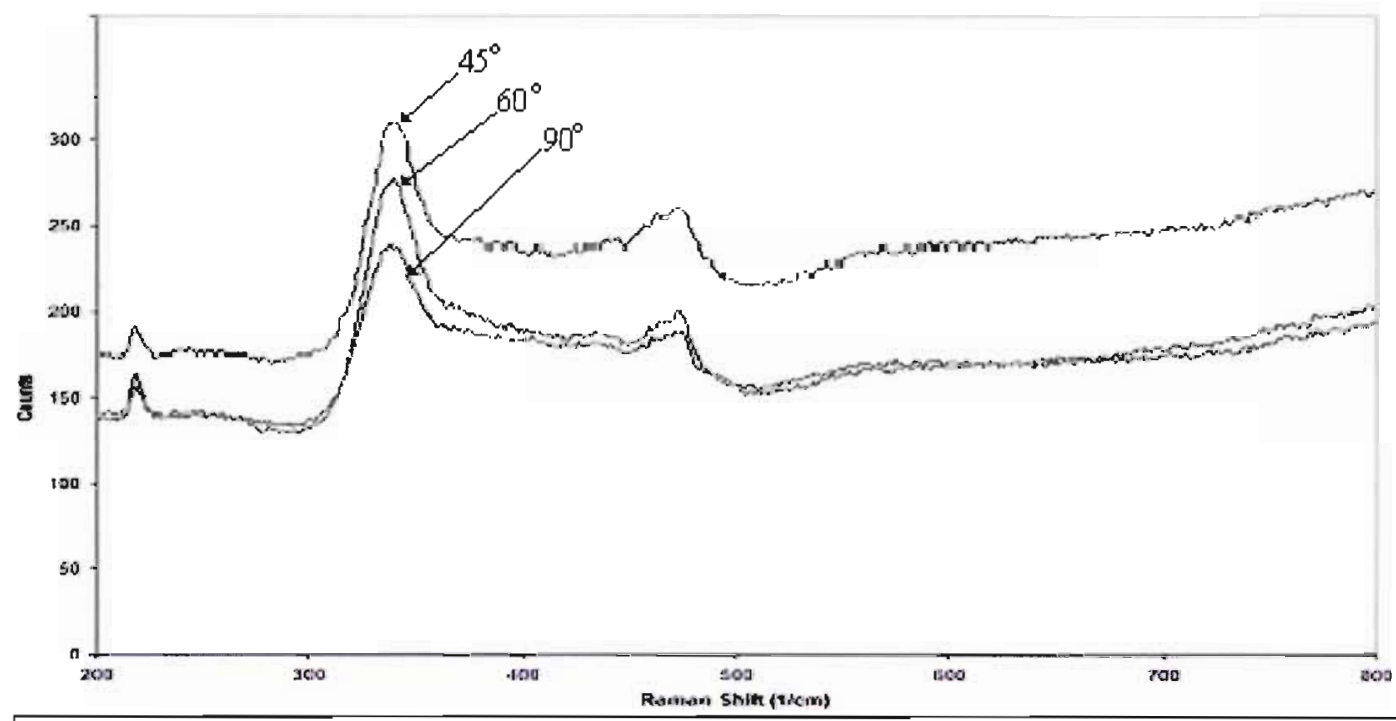

Figure 4.11: Raman Results from Virgin $45^{\circ}, 60^{\circ}$ and $90^{\circ}$ Slide 22

at 3 different angles $\left(90^{\circ}, 60^{\circ}\right.$ and $\left.45^{\circ}\right)$. After the deposition these samples were stored in a nitrogen box until they were shipped off for Raman spectroscopy. As would be expected, the Raman lineshapes of all three are identical. This result indicates that the deposition is homogeneous throughout the vacuum chamber. Composition wise, the AgGe-S thin films deposited at different angles did not show significant differences. 


\subsubsection{Thermal Annealing}

As mentioned before, thermal annealing had the possibility of reducing the amount of element sulfur in the thin films. Figures 4.12 and 4.13 show the Raman lineshapes for $\mathrm{Ag}-\mathrm{Ge}-\mathrm{S}$ thin films after being thermally annealed at $150^{\circ} \mathrm{C}$ and $200^{\circ} \mathrm{C}$,

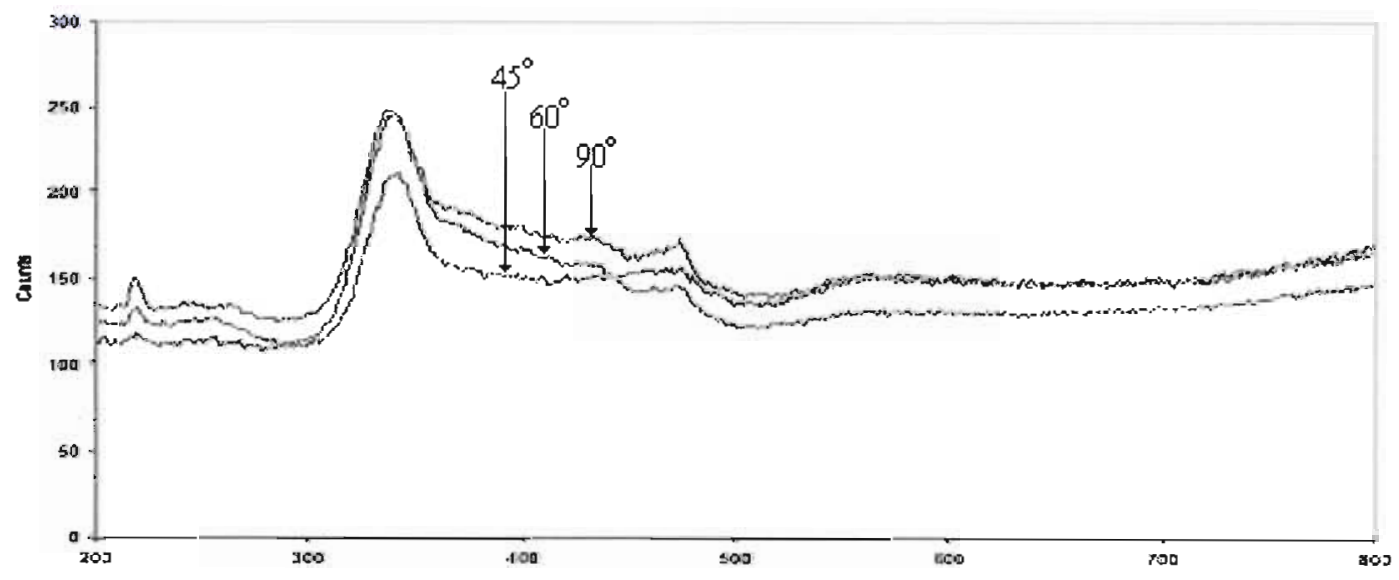

Figure 4.12: Raman Results from $45^{\circ}, 60^{\circ}$ and $90^{\circ}$ slide @ $150^{\circ} \mathrm{C}^{28}$

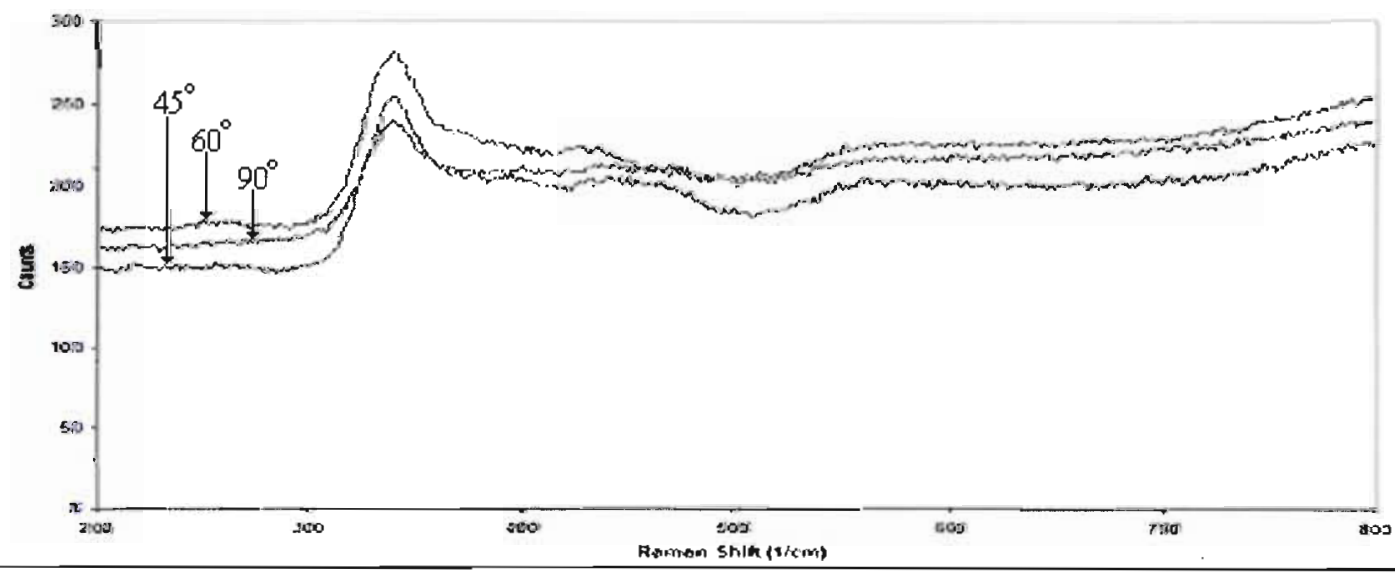

Figure 4.13: Raman Results from $45^{\circ}, 60^{\circ}$ and $90^{\circ}$ slide @ $200^{\circ} \mathrm{C}^{28}$

respectively. After annealing samples at $150^{\circ} \mathrm{C}$ for an hour, sulfur peaks from the $45^{\circ}$ sample were almost completely removed. ${ }^{28}$ The sulfur peaks for $60^{\circ}$ are also 
significantly reduced. The $90^{\circ}$ samples, however, look near unchanged. The results from the $200^{\circ} \mathrm{C}$ annealing treatment are significantly different than the $150^{\circ} \mathrm{C}$ ones. In the $200^{\circ} \mathrm{C}$ annealing treatment all the peaks of elemental Sulfur are all gone for all three samples.

Two conclusions can be drawn from these results. The first conclusion is that annealing the Ag-Ge-S glass thin films at $200^{\circ} \mathrm{C}$ will completely disperse the extra elemental Sulfur. Second, the angle at which the film is deposited determines how tightly packed the thin film is and, in turn, determines the ease at which elemental sulfur can be removed from the film. For example as the angle of deposition decreased in the $150 \mathrm{C}$ annealing treatment so did the removal of the elemental sulfur peaks. In summary the lower the deposition angle the less tightly packed the film is.

\subsubsection{Photo annealing}

Photo annealing was also performed on the Ag-Ge-S thin films deposited at 3 angles. As can be seen in figure 4.14, photo annealing had little to no effect in terms of reducing

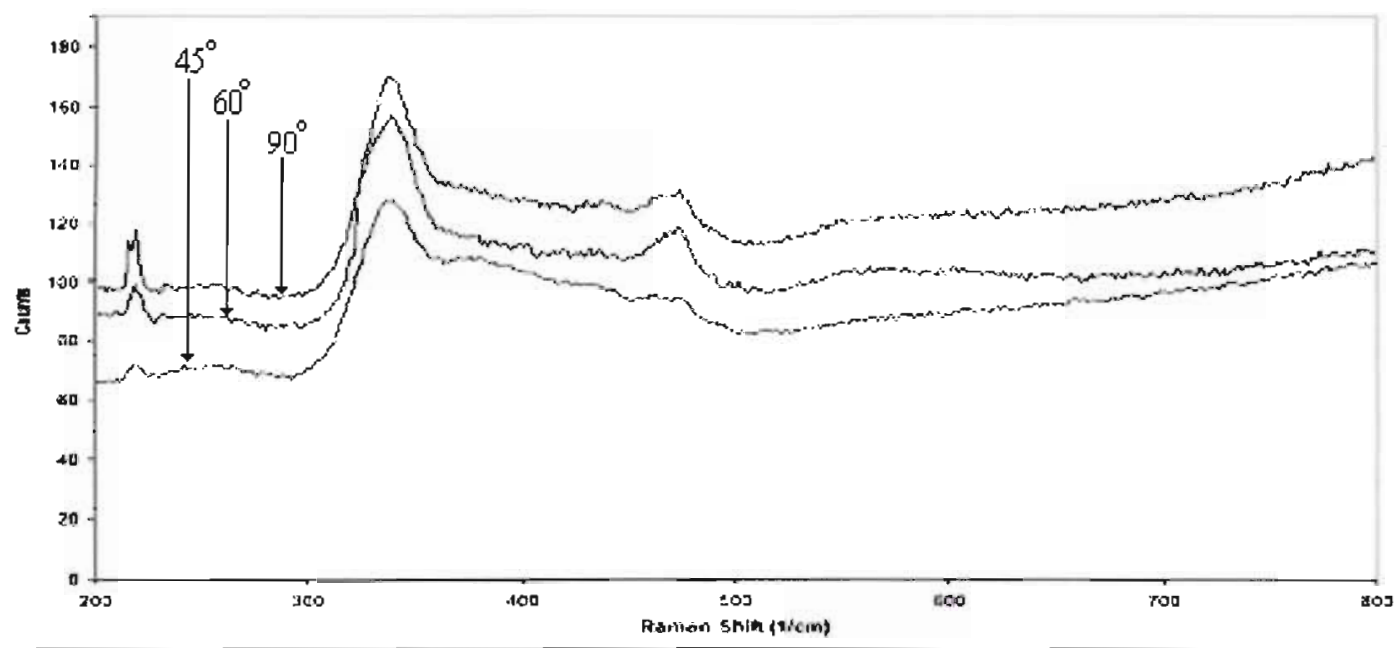

Figure 4.14: Raman Results from $45^{\circ}, 60^{\circ}$ and $90^{\circ}$ slide photo annealing ${ }^{28}$ 
the elemental Sulfur peaks. ${ }^{28}$ This is likely because the power of the UV light is not sufficient enough to make any difference.

\subsection{Device Results}

The current vs. voltage curve seen in figure 4.15 are results from a good Ag-Ge-S glass non volatile device. ${ }^{29}$ From the graph in figure 4.15 it can be seen that the device

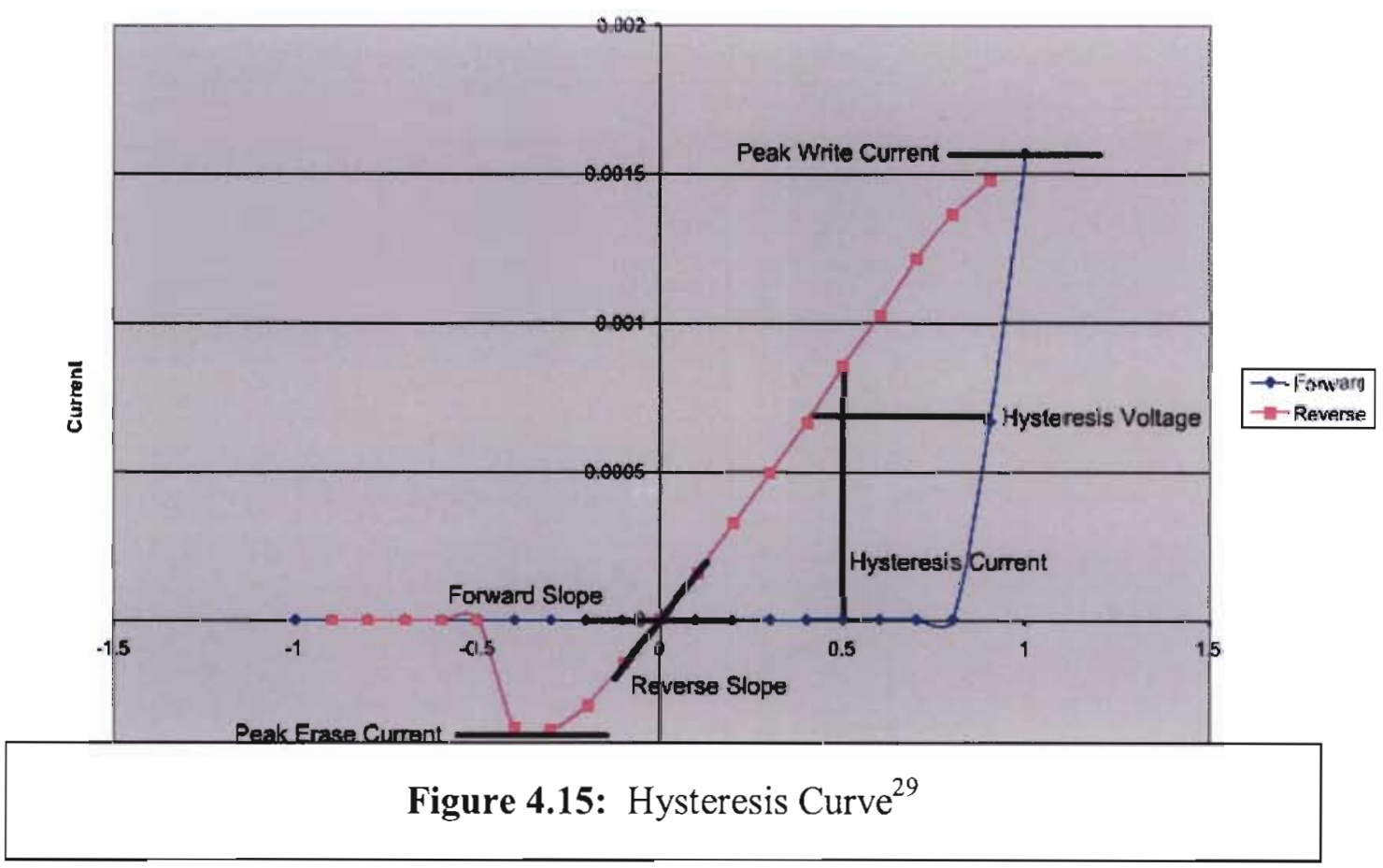

can be tuned between a low resistive state and a high resistive state just as theory predicts. The device switches from a high resistance to a low resistance state upon the application of $0.7 \mathrm{~V}$ bias, while it can be returned to a high resistance state upon application of $-0.5 \mathrm{~V}$ reverse bias. The measured on resistance is approximately $640 \Omega$, and the off resistance is approximately $210 \mathrm{k} \Omega$. The resistance difference between the on 
state and the off state is significant enough to be sensed using current sensors.

This device D3 is only one example of a fully functional device. Figures 4.164.18 are current vs. voltage graphs for 3 cycle of a working device.

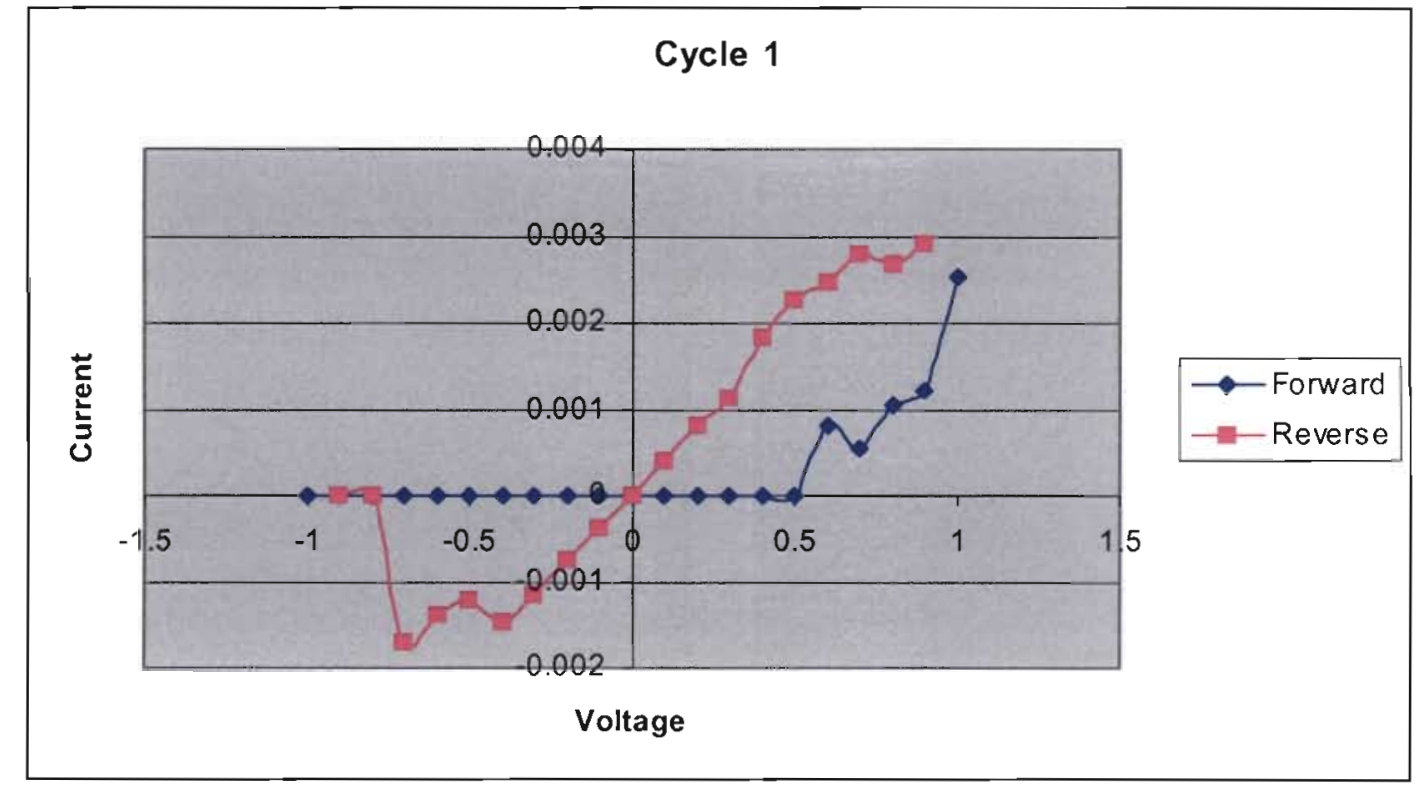

Figure 4.16: Current vs Voltage Device D3 1st Cycle

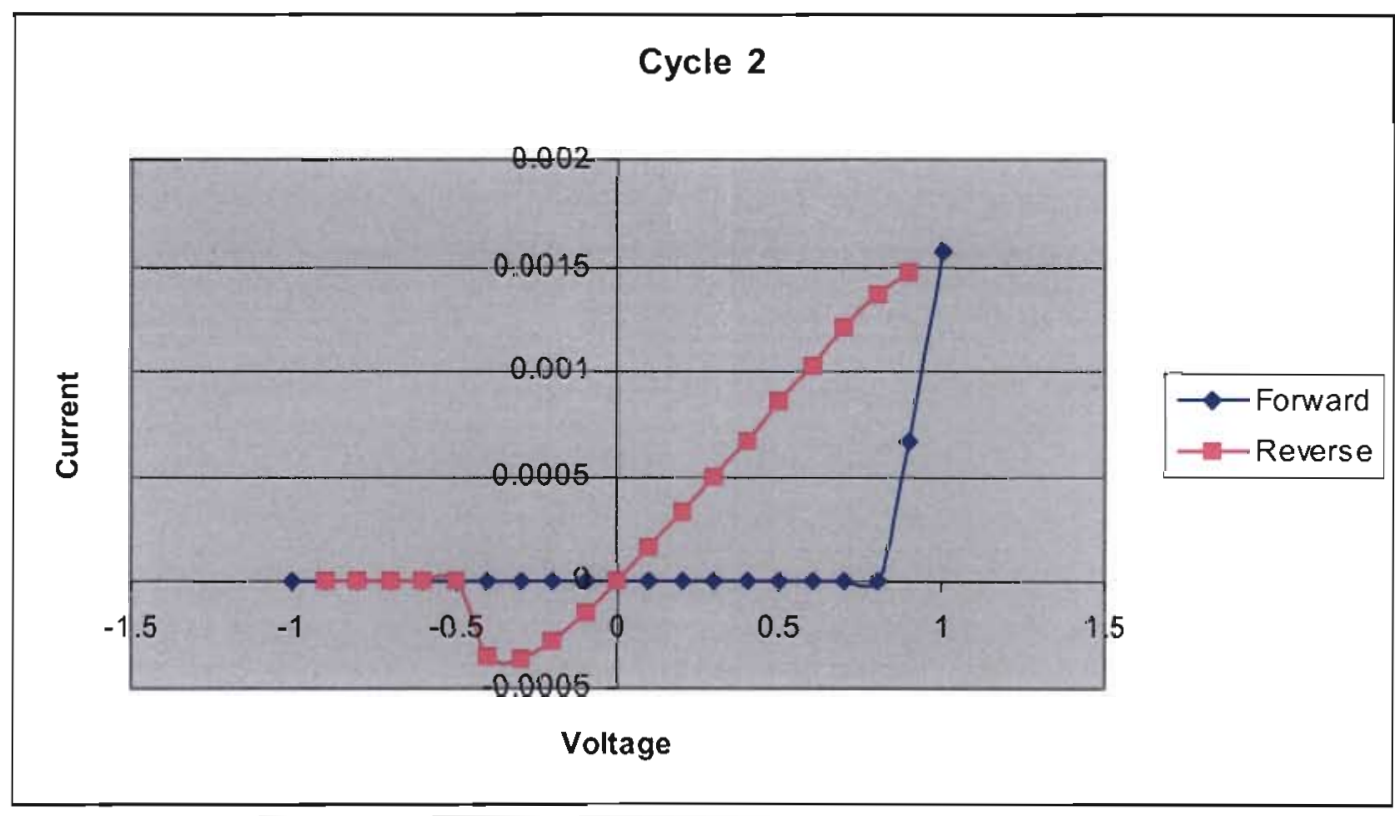

Figure 4.17: Current vs Voltage Device D3 2nd Cycle 


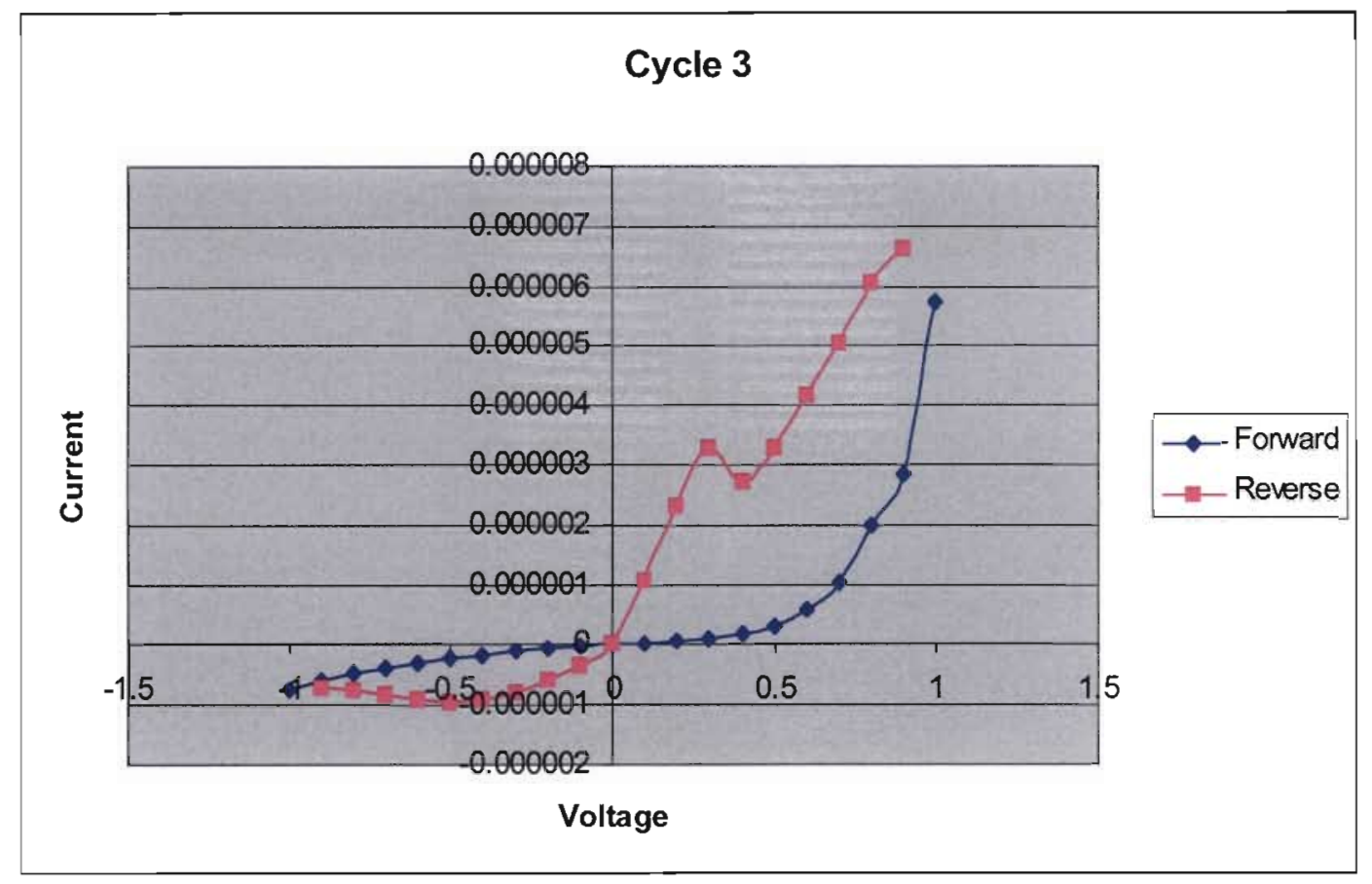

Figure 4.18: Current vs Voltage Device D3 3rd Cycle

Out of a total of the 192 individual devices that were fabricated, 176 were tested. The thickness of the chalcogenide layer for each set of slides varied from about $10 \mathrm{mg}-$ $120 \mathrm{mg}$ of material as can be seen in table 4.3. Of the 176 devices tested eight operated

\begin{tabular}{|c|c|c|c|c|c|c|}
\hline Device Slides & A \& B & C\&D & E \& F & G\&H & I \& J & K\& L \\
\hline Glass Am ount (mg) & 16 & 30 & 60 & 120 & 24.5 & 10 \\
\hline
\end{tabular}

Table 4.3: Amount of Glass per Device Slide

properly through all three cycles, 17 started good but the hysteresis curve gradually 
shrank and 175 were shorted, open or questionable. Of the devices that worked for all three cycles and the ones that worked for less than three cycles, the turn on voltage varied from 0.353 Volts to 0.733 Volts with the average being around 0.526 Volts as can be seen in table $4.4 .^{30}$

Besides the turn on voltage, table 4.4 contains the average peak write current,

\begin{tabular}{|c|c|c|c|c|c|}
\hline Device & B & $C$ & $D$ & $E$ & $F$ \\
\hline Peak Wite Current (mA) & $3.00 E-04$ & 1.132 & 3.58 & 27.032 & 35.595 \\
\hline Peak Erase Current (mA) & $-9.28 E-06$ & -1.111 & -1.135 & -17.816 & -17.984 \\
\hline Slope Difference (mA) & $2.33 E-05$ & 4.255 & 4.705 & 19.419 & 26.367 \\
\hline Hysteresis Voltage (V) & 0.229 & 0.29 & 0.259 & 0.252 & 0.253 \\
\hline Hysteresis Current (mA) & $7.71 E-05$ & 1.121 & 1.545 & 4.854 & 8.185 \\
\hline Turn On Voltage (V) & 0.733 & 0.353 & 0.442 & 0.624 & 0.48 \\
\hline Glass amount (mg) & 15 & 30 & 30 & 60 & 60 \\
\hline \hline
\end{tabular}

Table 4.4: Device Averages for Slides B-F $\mathrm{F}^{30}$

peak erase current, Hysteresis Voltage and Hysteresis Current for devices that functioned. ${ }^{30}$ The hysteresis Current is the difference between the on and off current at half a voltage and the hysteresis voltage is the voltage difference at half the current.

These values help describe the hysteresis curve of the devices. One interesting note is the thickness did not seem to influence the turn on voltage that much. All the different film widths had roughly a similar spread and average turn on voltages. Film thickness or glass 
amount, however, did have a significant impact on the write current, which in turn means a lower on resistance. The thicker the film the more glass used the higher the current, i.e. the lower the on resistance. This effect can be seen in figure 4.19.

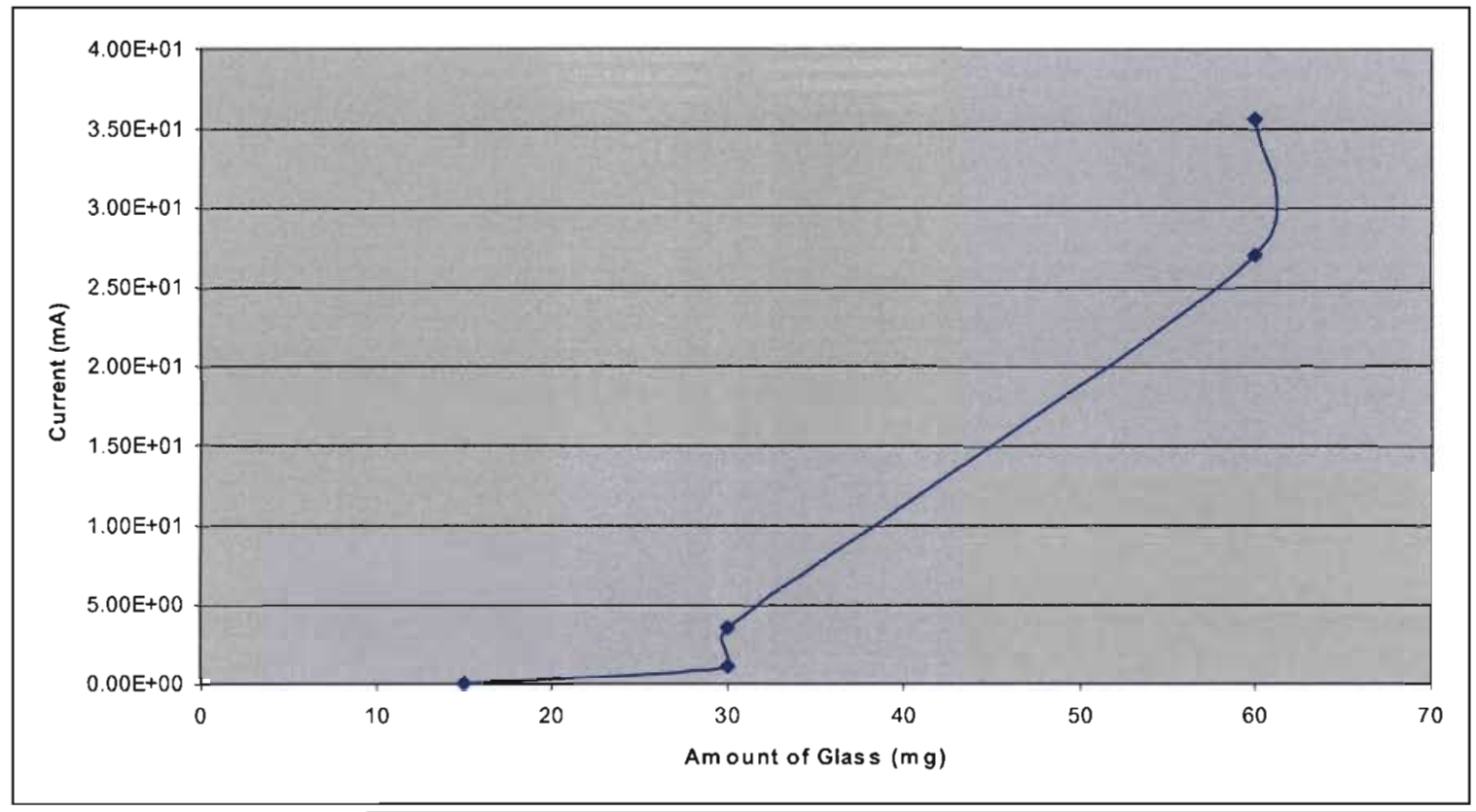

Figure 4.19: Current vs. Amount of Glass

After analyzing all the data taken, the devices had two common modes of failure that should be noted. The two primary modes of failure are the narrowing of the hysteresis curve and shorted devices. A few of the devices started with a good hysteresis curve and shrank with each successive read/cycle until it had a shape similar to that of a shorted device for examples of this mode of failure see figures 4.20 and 4.21. The "shorted" devices themselves are not a true short (see figure 4.22). If the device was shorted the I-V curve would be a straight line with the inverse of the slope of the line being the resistance, Resistance $=$ Voltage $/$ Current. The $\mathrm{I}-\mathrm{V}$ curves of our shorted 
devices resemble the I-V curve of a diode or PN junction. The group working on $\mathrm{Ag}_{2} \mathrm{~S}$ based devices out of MIT, as can be seen in figure 4.23 , have also observed a similar failure mode. ${ }^{10}$

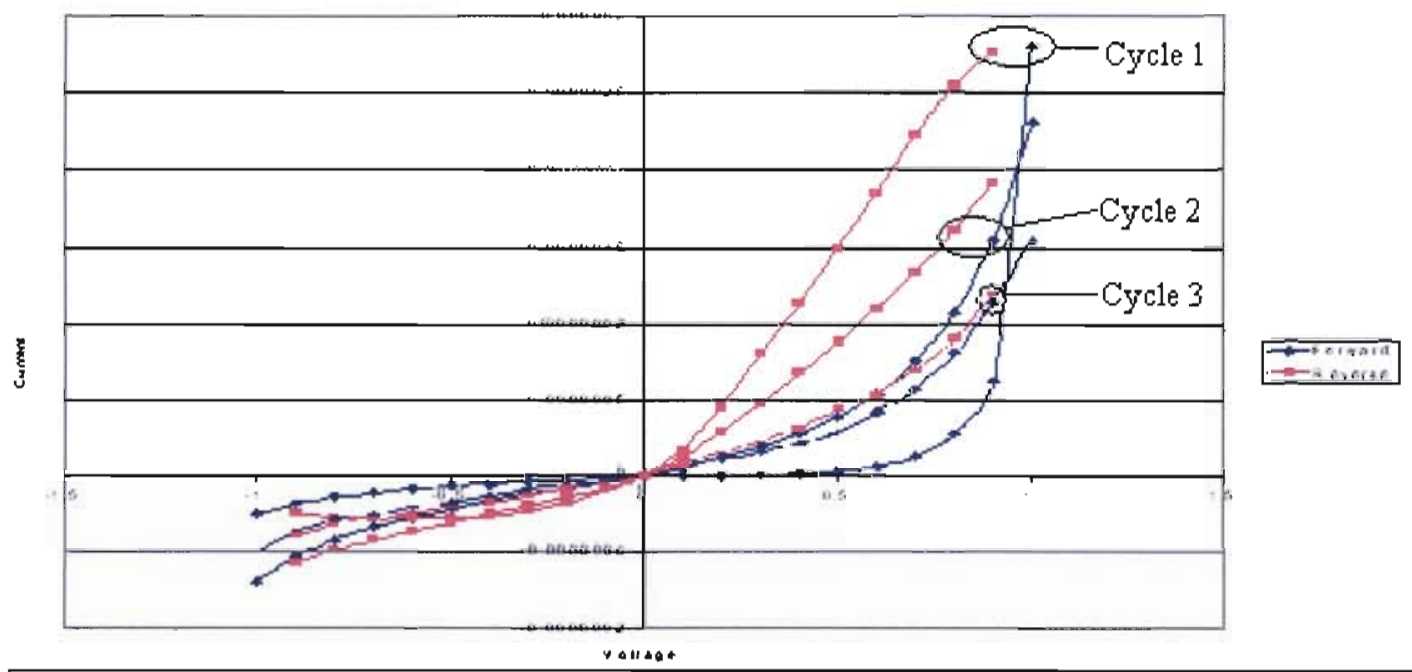

Figure 4.20: Narrowing of Hysteresis Curve Over Three Read/Write Cycles Device C3

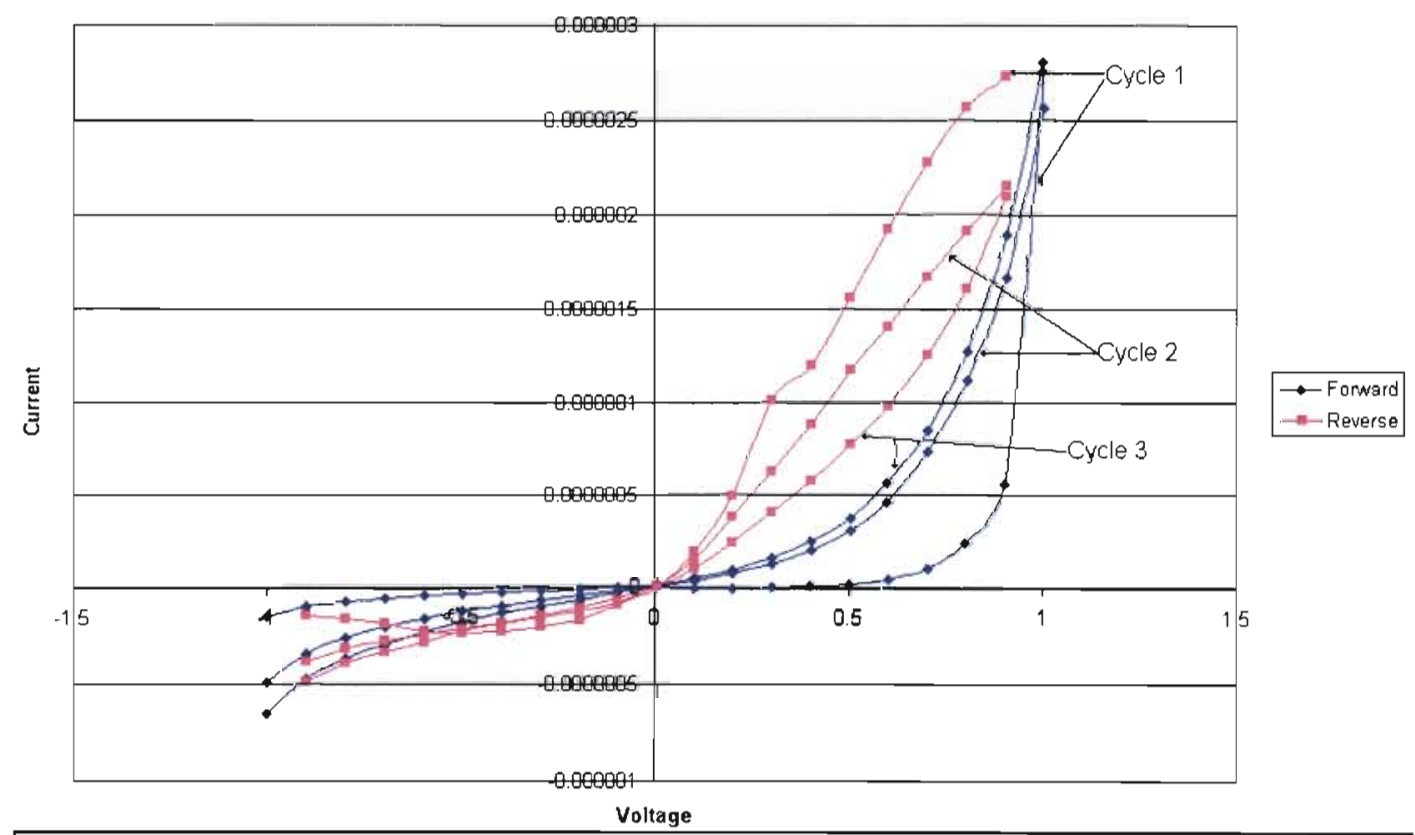

Figure 4.21: Narrowing of Hysteresis Curve Over Three Read/Write Cycles Device $\mathrm{C} 10$ 


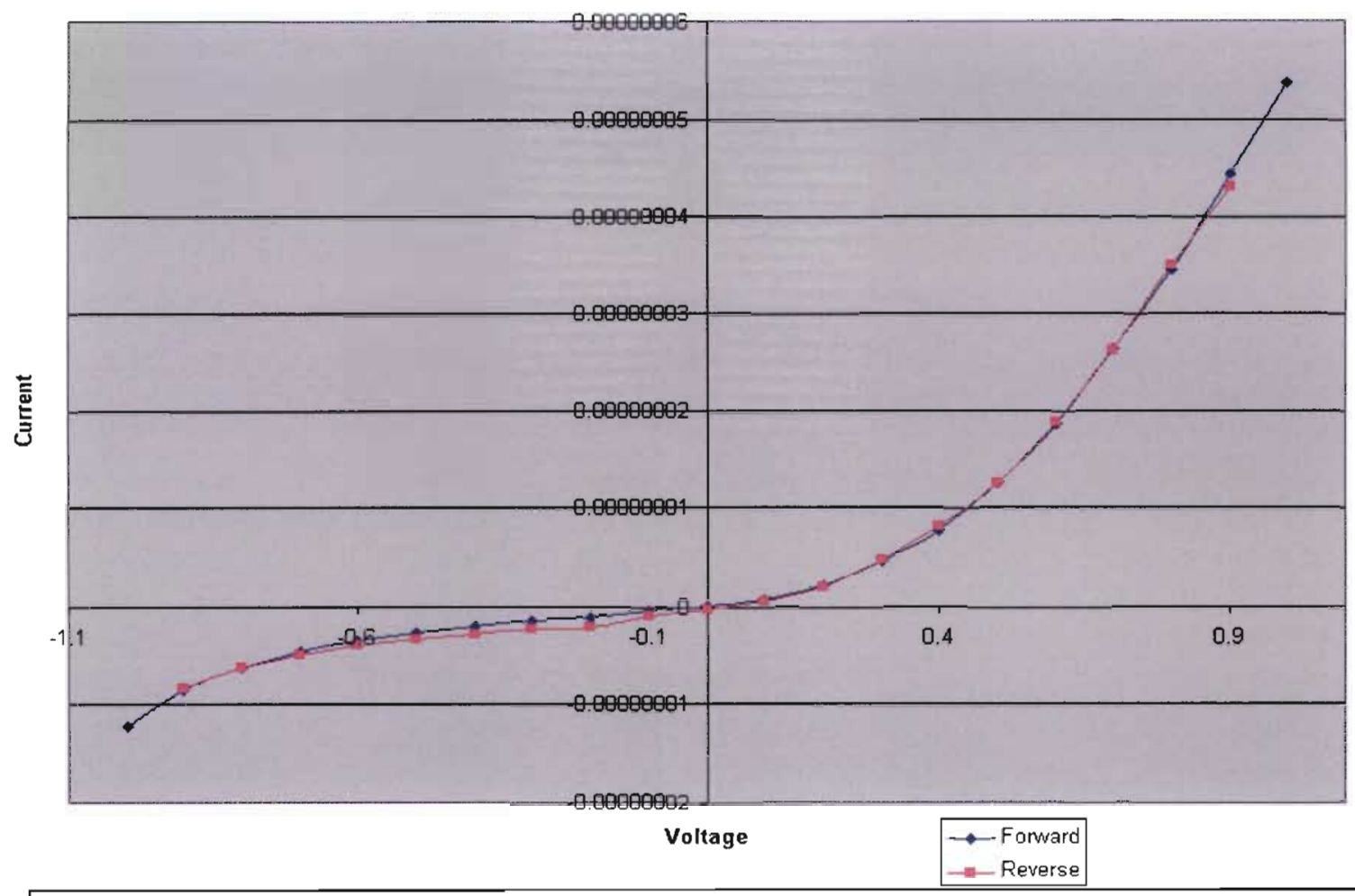

Figure 4.22: Shorted Device

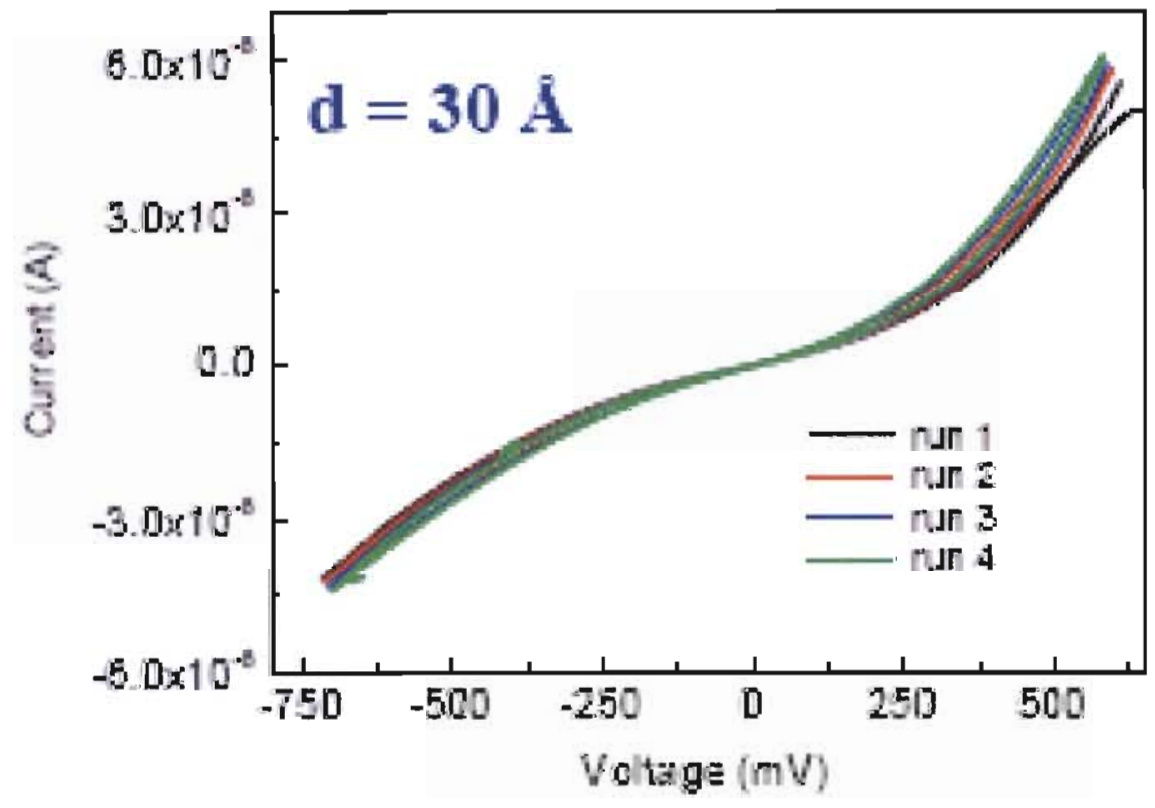

Figure 4.23: Failure Mode of Ag2S Device ${ }^{10}$ 


\section{Chapter 5: Concluding Remarks}

The purpose of this project was fabricating and testing a non-volatile memory device using a thin chalcogenide glass film consisting of $\left[\mathrm{Ag}_{x}\left(\mathrm{Ge}_{.75} \mathrm{~S}_{.25}\right)_{1-\mathrm{x}}\right]$. The work was done in two phases: 1) Ag-Ge-S thin film fabrication and characterization; 2) Nonvolatile memory device fabrication and characterization.

$\mathrm{Ag}-\mathrm{Ge}-\mathrm{S}$ thin films of compositions $\left[\mathrm{Ag}_{0.1}\left(\mathrm{Ge}_{.75} \mathrm{~S}_{25}\right)_{0.9}\right]$ and $\left[\mathrm{Ag}_{0.2}\left(\mathrm{Ge}_{.75} \mathrm{~S}_{.25}\right)_{0.8}\right]$ was deposited using thermal evaporation and characterized using Raman spectroscopy. The Raman lineshapes of the thin film Ag-Ge-S qualitatively agrees with that of the corresponding Ag-Ge-S bulk material. Thermal evaporation of Ag-Ge-S thin films yielded films with a non homogenous composition. Seen in the Raman lineshapes of the Ag-Ge-S are the signature peaks of elemental Sulfur, $\mathrm{S}_{8}$.

In an investigation into the reduction of elemental Sulfur and thickness of thin films grown vs the amount of material used, an oblique deposition experiment was performed. From this experiment it was apparent that as the distance between the source and substrate decreases, the thickness of the thin film increases. In addition to that, we observed that the packing density decreases as the angle of deposition is lowered.

The packing factor and deposition angle correlation came from thermal annealing one sample of each angle. At $150^{\circ} \mathrm{C}$ the elemental sulfur in the $45^{\circ}$ sample is completely removed, the $60^{\circ}$ sample is reduced and the $90^{\circ}$ sample looks relatively unchanged.

These results happened because the amount of energy required to dissolve or remove the elemental sulfur was decreased as the packing density decreased. At $200^{\circ} \mathrm{C}$, however, the thermal energy provided was enough to remove all of the elemental Sulfur from each of the three different sample angles. 
The second half of the project focused on the fabrication of Non-volatile memory devices using the resistance switching properties of Ag-Ge-S chalcogenide glass thin films. For selected working devices, the resistance switched between $640 \Omega$ and $210 \mathrm{k} \Omega$. Devices were fabricated as a function of $\mathrm{Ag}-\mathrm{Ge}-\mathrm{S}$ thin film thickness. This was done to determine the optimal thickness of device operation and the device characteristics dependence on the thickness of the of Ag-Ge-S chalcogenide glass thin film. The devices functioned best between the 15-30 nm range based on functioning device yield. From the device data the switching threshold voltage had no dependence on the thickness of the Ag-Ge-S chalcogenide glass thin film. The current on the other hand was proportional to the thickness of the Ag-Ge-S chalcogenide glass thin films, a thicker film supports a larger current.

Out of 192 devices, 8 functioned properly, 17 functioned properly initially and the majority were shorted. The high device failure was expected given the method of fabrication and the equipment used. The group from University of Phoenix Arizona that experimented with devices based on $\mathrm{Cu}-\mathrm{Ge}-\mathrm{S}$ chalcogenide glass had results similar to the 17 initially good devices which, had one good cycle then gradually narrowed until it resembled a shorted device. ${ }^{25}$ Similar results were also obtained by a MIT group working on $\mathrm{Ag} 2 \mathrm{~S}$ Devices. ${ }^{10}$ The exact reason for the shorted mode of failure remains to be understood.

Before chalcogenide based devices can be put into commercial use there are still several issues that require further study. ${ }^{31}$ These issues include the fabrication of chalcogenide films with higher homogeneity, integration of chalcogenide devices with Silicon devices, the effects if any of oxidation layers between electrodes and the 
chalcogenide glass thin films, scalability of devices and a functional mathematical model of the workings of chalcogenide devices. 


\section{References:}

1. Linda Geppert. "The New Indelible Memories: It's a three-way race in the multibillion-dollar memory sweepstakes.” IEEE Spectrum March 2003.

2. Michael N. Kozicki, Chakavarthy Gopalan, Murali Balakrishnan, Mira Park and Maria Mitkova. Non-Volatile Memory Based on Solid Electrolytes. Center for Solid State Electronics Research, Arizona State University. IEEE 2004.

3. Semyon D. Savransky. "Model of OFF-ON Transition and SET Process in PhaseChange Memory." IEEE 2005.

4. A. Redaelli, A. Pirovano, F. Pellizzer, A.L. Lacaita, D. Ielmini and R. Bez. "Electronic Switching Effect and Phase-Change Transition in Chalcogenide Materials." IEEE Electron Device Letters, Vol. 25. No 10, p 648-686, IEEE September 2004.

5. A.V. Pohm, C.H. Sie, R.R. Uttecht, V. Kao and O. Agrawal. "Chalcogenide Glass Bistable Resistivity (Ovonic) Memories.” IEEE Transactions on Magnetics, $p$ 592-593, IEEE 1970.

6. M. Mitkova and M.N. Kozicki. "Silver Incorporation in GE-Se Glasses Used in Programmable Metallization Cell Devices." Journal of Non-Crystalline Solids p 299-302, Elsevier Science B.V. 2002.

7. Michael N. Kozicki, Chakavarthy Gopalan, Murali Balakrishnan, Mira Park and Maria Mitkova. "Non-Volatile Memory Based on Solid Electrolytes". Center for Solid State Electronics Research, Arizona State University. IEEE 2004. p 12. 


\section{References:}

8. S. Prakash, S. Asokan and D.B. Ghare. "A Guideline for Designing ChalcogenideBased Glasses for Threshold Switching Characteristics." IEEE Electron Device Letters. Vol. 18, No 2, p 45-47, IEEE February 1997.

9. M.N. Kozicki, M. Mitkova, J. Zhu and M. Park. "Nanoscale separation in Ag-Ge-Se Glasses. Microelectronics Engineering, issue 63, p 155-159, Elsevier 2002.

10. I. Chaitanya Lekshmi, Yasmin Afsar T. Nagahama, G. Miao, T. Santos and J. S. Moodera. "Metal-semiconductor-metal junctions with silver sulphide barrier layer." Presented at the March 2006 APS Meeting. Francis Bitter Magnet Lab, MIT Cambridge, MA

11. M.N. Kozicki, M. Yun, S. J. Yang, J.P. Aberouette and J.P. Bird. "Nanoscale Effects in Devices Based on Chalcogenide Solid Solutions." Superlattices and Microstructures, Vol 27, No 5/6, Academic Press 2000.

12. Patrick K. Herring and Kristy A. Campbell. Resistance Switching in $\mathrm{Sn}_{\mathrm{x}} \mathrm{Mn}_{\mathrm{y}} \mathrm{Te}_{z^{-}}$ Based Devices. micron Technology, inc. IEEE 2006.

13. Fei Wang. "Research on Low Power Non-Volatile Information Storage Device Based on Novel Chalcogenide Material." Project Overview Cal Poly State University San Luis Obispo 2006.

14. National Institute of Standards and Technology. "Raman Spectroscopy" http://physics.nist.gov/Divisions/Div844/facilities/raman/Ramanhome.html (accessed on 1/18/08)

15. "Aluminum". Wikipedia: The Free Encyclopedia. http://en.wikipedia.org/wiki/Aluminum (accessed on 12/27/07). 


\section{References:}

16. "Germanium". Wikipedia: The Free Encyclopedia.

http://en.wikipedia.org/wiki/Germanium (accessed on 12/27/07).

17. "Silver". Wikipedia: The Free Encyclopedia.

http://en.wikipedia.org/wiki/Silver (accessed on 12/27/07).

18. "Sulfur". Wikipedia: The Free Encyclopedia.

http://en.wikipedia.org/wiki/Sulfur (accessed on 12/27/07).

19. R. D. Mathis: Product Catalog. Figure 9 p. 6.

http://www.rdmathis.com/catalog/page3.html (accessed on 01/18/08).

20. R. D. Mathis: Product Catalog. Figure 4 p. 12.

http://www.rdmathis.com/catalog/page6.html (accessed on 12/28/07)

21. R. D. Mathis: Product Catalog. Figure 7 p. 13.

http://www.rdmathis.com/catalog/page6.html (accessed on 01/18/08)

22. R. D. Mathis: Product Catalog. Figure $6 \& 7$ p. 27.

http://www.rdmathis.com/catalog/page8.html (accessed on 01/18/08)

23. R. D. Mathis: Product Catalog. Figure 6 p. 15.

http://www.rdmathis.com/catalog/page6.html (accessed on 12/28/07)

24. P. Boolchand, Fei Wang, U. Vempati, M. Mitkova, M. Kozicki, "Bimodal Glass

Transition Temperature (Tgs) and Macroscopic Phase Separation In $\operatorname{Ag}_{x}\left(G_{x} S_{1-x}\right)_{y}$

glasses" Session N15, APS March Meeting Bulletion, Vol. 2, N15-13, P826

(2004) 


\section{References:}

25. M.N. Kozicki, M. Balakrishnan, C. Gopalan, C. Ratnakumar, and M. Mitkova. "Programmable Metallization Cell Memory Based on Ag-Ge-S and Cu-Ge-S Electrolytes." Center for Solid State Electronics Research, Arizona State University. IEEE 2005. p.87

26. F. Wang and P. Boolchand. APS March Meeting, Montreal, Canada 2004

27. Bentor, Yinon. Chemical Element.com - Sulfur. http://www.chemicalelements.com/elements/s.html. (Jan. 19, 2008)

28. Carter De Leo. Senior Project, California Polytechnic University of California. Spring 07. p. 14-16

29. Carter De Leo. Senior Project, California Polytechnic University of California. Spring 07. p. 22

30. Carter De Leo. Senior Project, California Polytechnic University of California. Spring 07. p. 23

31. Michael N. Kozicki, Mira Park and Maria Mitkova. 'Nanoscale Memory Elements Based on Solid-State Electrolytes." IEEE Transactions on Nanotechnology, Vol. 4, No 3, p 331-338. IEEE 2005. p. 337. 